\title{
Different co-culture systems have the same impact on bovine embryo transcriptome
}

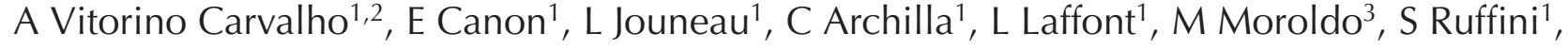 \\ E Corbin $^{2}$, P Mermillod $^{2}$ and V Duranthon ${ }^{1}$ \\ ${ }^{1} U M R B D R$, INRA, ENVA, Université Paris Saclay, Jouy-en-Josas, France, ${ }^{2} U M R$ PRC, INRA, CNRS, IFCE, Université \\ de Tours, Nouzilly, France and ${ }^{3} \mathrm{GABI}$, INRA, AgroParis Tech, Université Paris-Saclay, Jouy-en-Josas, France \\ Correspondence should be addressed to A Vitorino Carvalho or V Duranthon; Email: anais.carvalho@hotmail.fr \\ or veronique.duranthon@inra.fr
}

\begin{abstract}
During the last few years, several co-culture systems using either BOEC or VERO feeder cells have been developed to improve bovine embryo development and these systems give better results at high oxygen concentration (20\%). In parallel, the SOF medium, used at $5 \% \mathrm{O}_{2}$, has been developed to mimic the oviduct fluid. Since 2010s, the SOF medium has become popular in improving bovine embryo development and authors have started to associate this medium to co-culture systems. Nevertheless, little is known about the putative benefit of this association on early development. To address this question, we have compared embryo transcriptomes in four different culture conditions: SOF with BOEC or VERO at $20 \% \mathrm{O}_{2}$, and SOF without feeders at $5 \%$ or $20 \% \mathrm{O}_{2}$. Embryos have been analyzed at 16-cell and blastocyst stages. Co-culture systems did not improve the developmental rate when compared to $5 \% \mathrm{O}_{2}$. Direct comparison of the two co-culture systems failed to highlight major differences in embryo transcriptome at both developmental stages. Both feeder cell types appear to regulate the same cytokines and growth factors pathways, and thus to influence embryo physiology in the same way. In blastocysts, when compared to culture in SOF at $5 \% \mathrm{O}_{2}$, BOEC or VERO seems to reduce cell survival and differentiation by, at least, negatively regulating STAT3 and STAT5 pathways. Collectively, in SOF medium both blastocysts rate and embryo transcriptome suggest no influence of feeder origin on bovine early development and no beneficial impact of co-culture systems when compared to $5 \% \mathrm{O}_{2}$.

Reproduction (2017) 154 695-710
\end{abstract}

\section{Introduction}

In mammals, one of the most critical steps for a successful pregnancy is the early development of the embryo. In cattle, the largest part of embryo loss occurs before day 16 following breeding (about 40\% of pregnancy loss) with some evidence of greater losses before day 8 in high-producing dairy cows (Humblot 2001, Diskin \& Morris 2008). The early pregnancy mainly occurs in the oviduct, which provides the optimum environment for the final preparation, transport and survival of gametes, the fertilization process and early embryonic development. After fertilization, the zygote, under the influence of the maternal genome represented by mRNA and proteins in oocyte cytoplasm, undergoes several cell divisions to the 8-16-cell stage where its own genome begins expressing (Telford et al. 1990). Then, cells start interacting together which leads to compaction at the morula stage (32-64 cells). This step occurs about 4-5 days after fertilization, when embryo leaves the oviduct to enter the uterus. The embryo then cavitates (the blastocoele appears) and the first cell differentiation occurs at the blastocyst stage, about 7 days after fertilization (Guillomot 1995). During all these steps, the embryo is free-living in the oviduct and influenced by its surrounding environment which can modulate gene expression patterns, epigenetic mechanisms and embryo metabolism, leading to a modification of morphology and developmental potential of the embryo (Watkins et al. 2008). Effective embryo-maternal crosstalk is necessary for successful early development and viability of the embryo (Leese et al. 2008, Kolle etal. 2010, Gad et al. 2012). Although some oviduct secretions are identified as chemokines, cytokines, growth factors and apoptosis regulators (Kolle et al. 2010), little is known about crucial factors for early development of embryo.

Nowadays, protocols of in vitro fertilization (IVF) and theembryoculturearewell established in various mammal species, including cattle. Nevertheless, in 1990s, in vitro embryo production was a challenge due the observed arrest of embryo development at the embryonic genome activation (EGA) stage (Rieger et al. 1995). To improve in vitro development of zygotes, co-culture systems were developed using oviduct epithelial cells (OECs), first in sheep (Gandolfi \& Moor 1987) and in cattle 
(Eyestone \& First 1989) and then in mouse (Watkins et al. 2008). Classically, OEC are obtained from fresh oviducts and can be cultivated in different configurations: in suspension of vesicles (Eyestone \& First 1989, Walter 1995, Rottmayer et al. 2006, Lopera-Vasquez et al. 2016), plated as monolayer (Ouhibi et al. 1989, Walter 1995, Cordova et al. 2014, Schmaltz-Panneau et al. 2014, 2015) or on membrane supports (Rief et al. 2002, Tahir et al. 2011). However, at the moment, the simplest method to perform this protocol remains the monolayer BOEC (Cordova et al. 2014, Schmaltz-Panneau et al. 2014, 2015). This protocol results in higher blastocyst rates at high oxygen concentration $\left(20 \% \mathrm{O}_{2}\right)$ than that at low oxygen level $\left(5 \% \mathrm{O}_{2}\right)$ (Clemente et al. 2008). Despite vast improvement of bovine embryo development due to the use of bovine oviduct epithelial cells (BOEC), this co-culture system proved inappropriate for commercial production in terms of efficiency, cost and sanitary controls (Pegoraro et al. 1998, Rief et al. 2002). But it remains a suitable model for studying embryo-maternal interactions in vitro (Clemente et al. 2008). Nonetheless, several studies have reported drastic morphological changes when BOEC were cultured in monolayers (Rief et al. 2002, Tahir et al. 2011) and variation of gene expression (Schmaltz-Panneau et al. 2015) all along the BOEC culture. This suggested that their influence on embryo development could be altered along the co-culture.

In parallel to this, other co-culture systems were developed based on exogenous cells. Several established cell lines were used to improve bovine embryo development and quality, including VERO cells (Carnegie et al. 1997, Menck et al. 1997). VERO cells are a well-defined, established epithelial cell line derived from the kidney of green monkey (Cerpopithecus aethiops). This tissue has a common origin with the genital tract (mesoderm) (Lai et al. 1996a, Duszewska et al. 2000). These cells were chosen as a sanitary safe support for mammal embryo development (Menezo et al. 1990). The culture of VERO implies high oxygen concentration $\left(20 \% \mathrm{O}_{2}\right)$ (Ammerman et al. 2008). At this high oxygen concentration, VERO cells improve the kinetic of embryo development, blastocyst rate, blastocyst cell number, blastocyst cryotolerance and late pregnancy rate in B2 medium (Ouhibi et al. 1989, Menck et al. 1997, Carnegie et al. 1999). As in the case of BOEC, the presence of VERO during bovine early development provides embryotrophic factors (Gandolfi \& Moor 1987, Lai et al. 1996b), including growth factors (Mermillod et al. 1993), removes toxic substances from medium (Bavister 1995, Duszewska et al. 2000), reduces $\mathrm{O}_{2}$ tension (Watson et al. 1994) and reduces glucose concentration in medium that inhibits embryo development (Bavister 1995). Nevertheless, to the best of our knowledge, no information is available about the influence of these two co-culture systems on embryo transcriptome. The comparison of embryo transcriptome co-cultured with BOEC and VERO would lead to the identification of embryonic biological pathways regulated by these co-culture systems and may help in understanding the influence of specific oviductal factors on bovine early development.

Independently, Tervit and coworkers designed a new culture medium to mimic the oviduct fluid, named synthetic oviduct fluid (SOF), which was able to support the early development of sheep and bovine embryos from the zygote to the blastocyst stages (Tervit et al. 1972). Several analyses showed that this medium presented better results in terms of blastocyst rate and quality when the oxygen level during the culture was low i.e. $5 \%$ vs $20 \% \mathrm{O}_{2}$ (Takahashi et al. 2000, Lequarre et al. 2003, Rho et al. 2007). However, the SOF medium started to be widely used for bovine embryo culture only in the last years, including in the case of co-culture systems (Al Darwich et al. 2010, Lopera-Vasquez et al. 2016). Despite it has been designed to be used at $5 \%$ $\mathrm{O}_{2}$, few analyses, focused on BOEC co-culture, used it at $20 \% \mathrm{O}_{2} \cdot$ In this condition, blastocyst rate and quality were improved compared to SOF only (at $20 \%$ $\mathrm{O}_{2}$ ) (Schmaltz-Panneau et al. 2015). To the best of our knowledge, the use of VERO co-culture system in SOF medium has not been reported yet. Consequently, little information is available on the putative beneficial impact of these two co-culture systems, previously described with B2 or TCM199 medium, on bovine early development in SOF medium and more specially, on the embryo transcriptome.

Here, we have analyzed the transcriptome of 16-cell and blastocyst embryos, cultured in SOF medium in the absence or presence of the two feeder cells types previously described, namely BOEC and VERO cells. These two developmental stages were chosen because the impact of embryo environment is particularly important at the stage of the embryonic genome activation (8-16 cell stage in bovine) (Leese et al. 2008, Watkins et al. 2008, Kolle et al. 2010, Gad et al. 2012) and because the major impact of BOEC on embryo development was described at the blastocyst stage in SOF medium (Cordova et al. 2014, Schmaltz-Panneau et al. 2014, 2015). Both co-culture systems were used with the optimal oxygen concentration previously described as $20 \% \mathrm{O}_{2}$ (Clemente et al. 2008, Cordova et al. 2014). Moreover, for a direct comparison, this high oxygen concentration was included as a control condition, as previously described (Cordova et al. 2014). Furthermore, to represent an 'optimal' culture condition without feeder cells, another control condition was added: SOF at $5 \% \mathrm{O}_{2}$. Interestingly, this condition is classically used in IVF protocols in SOF medium and is closer to in vivo condition (Takahashi et al. 2000, Lequarre et al. 2003, Rho et al. 2007, Amin et al. 2014). By comparing the embryo transcriptomes at these two stages and in these different culture conditions, we explored the influence of feeder origin on embryo gene expression and the 
impact of co-culture systems on early development in SOF medium, to identify factors secreted by feeders influencing bovine early embryo and analyze the benefits of co-culture systems in SOF medium.

\section{Materials and methods}

All bovine biological materials were sampled at a commercial slaughterhouse (Socopa, Le Neubourg, France) with the agreement of the boards of the slaughterhouse and of the local sanitary services.

\section{Primary BOEC cultures}

As previously described, primary BOEC cultures were obtained from oviduct collected from the slaughterhouse (Cordova et al. 2014, Schmaltz-Panneau et al. 2014, 2015). Ipsilateral oviducts attached to ovaries showing pre-ovulatory follicle or early ovulation sites were brought from the slaughterhouse within $3 \mathrm{~h}$ to our laboratory, without liquid at $32^{\circ} \mathrm{C}$ (Ulbrich et al. 2010). Oviducts were dissected and washed with washing medium (M199 modified Hepes - Sigma M7528, $25 \mathrm{mg} / \mathrm{L}$ gentamicin - Sigma G1272 - and 0.4 g/L bovine serum albumin (BSA), Sigma A6003; Sigma-Aldrich) at $39^{\circ} \mathrm{C}$. Oviductal mucosa was carefully expelled by squeezing the oviduct with a sterile glass slide, and washed three times with washing medium after gravity sedimentation for $5 \mathrm{~min}$. At least 3 independent oviducts were pooled during the washing step. The cells were subsequently frozen in a freezing medium (M199 - Sigma M4530, 10\% dimethyl sulfoxide (DMSO) Hybri-max, Sigma D2650, 20\% fetal bovine serum (FBS), Sigma F9665 and 40 mg/L gentamicin, Sigma G1272) with $150 \mu \mathrm{L}$ of BOEC per $1.5 \mathrm{~mL}$ of freezing medium at $-80^{\circ} \mathrm{C}$ and then stored in liquid nitrogen until experimentation. For experiments, cells were warmed at $37^{\circ} \mathrm{C}$ for $5 \mathrm{~min}$ and then, washed 2 times in $10 \mathrm{~mL}$ of seeding medium (M199 - Sigma M4530, 10\% FBS, Sigma F9665, 80 mg/L gentamicin, Sigma G1272). Cells were seeded into 4-well NUNC plates (167063, Thermo Fisher Scientific) with $500 \mu \mathrm{L}$ of seeding medium per well. During the cell culture, media was first changed after 48 h with BOEC culture medium (M199 - Sigma M4530, 10\% FBS, Sigma F9665 and $40 \mathrm{mg} / \mathrm{mL}$ gentamicin, Sigma G1272) and only $50 \%$ of media was replaced every $48 \mathrm{~h}$ until day 7 when BOEC had formed a confluent monolayer.

\section{VERO culture}

A frozen sample of the established VERO cell line was provided by Rhone-Mérieux (Lyon, France; Menck et al. 1997). As previsouly published (Menck et al. 1997), a culture was established from the frozen cryotube containing $4 \times 10^{6}$ cells. All VERO cultures were performed from the same multiplied frozen native cryotube. Briefly, after thawing, VERO cells were washed 3 times with M199 modified Hepes (Sigma M7528). Then, $10^{3}$ VERO cells were seeded in each well of 4-well NUNC plate (167063, Thermo Fisher Scientific) with $500 \mu \mathrm{L}$ BOEC culture medium (M199 - Sigma M4530, 10\% FBS, Sigma F9665 and $40 \mathrm{mg} / \mathrm{mL}$ gentamicin, Sigma G1272) at $39^{\circ} \mathrm{C}$ in $5 \% \mathrm{CO}_{2}$ in air. $50 \%$ of media was replaced every $48 \mathrm{~h}$ until day 4 when confluence was reached.

\section{Oocytes maturation and embryo production by in vitro fertilization (IVF)}

As previously described, embryo were produced by IVF (Menck et al. 1997). Bovine ovaries were collected from the slaughterhouse and brought within $3 \mathrm{~h}$ to the laboratory, in sterile Euroflush medium (IMV technologies, 019450) at $32^{\circ} \mathrm{C}$. Oocytes were aspired from follicles with $2-8 \mathrm{~mm}$ diameter and cumulus oocyte complexes (COCs) were placed in the maturation medium (M199 - Sigma M4530, 10\% FBS Gibco 10500-064, $10 \mu \mathrm{g} / \mathrm{mL}$ pLH - Reprobiol PLH, $10 \mu \mathrm{g} /$ $\mathrm{mL}$ Stimufol - Reprobiol 6911205, $1 \mu \mathrm{g} / \mathrm{mL} \beta$-Estradiol Sigma E4389, $50 \mu \mathrm{g} / \mathrm{mL}$ gentamicin - Sigma G1264) for $24 \mathrm{~h}$ at $39^{\circ} \mathrm{C}$ in $5 \% \mathrm{CO}_{2}$ in air. All fertilizations were performed with the same batch of frozen bull semen. After thawing, motile sperm was selected by the swim up technique with a discontinuous BoviPure/BoviDilute $(40 \% / 80 \%$, J.C.D. International Laboratory, L'Aigle, France) density gradient. Pools of 100 mature oocytes were fertilized with $10^{6}$ motile spermatozoa per $\mathrm{mL}$ during $18 \mathrm{~h}$ at $39^{\circ} \mathrm{C}$ and $5 \% \mathrm{CO}_{2}$ in IVF medium $\left(100 \mathrm{mM} \mathrm{NaCl}\right.$ - Sigma S5886, $3 \mathrm{mM} \mathrm{NaH}_{2} \mathrm{PO}_{4}-$ VWR 28015-294, $25 \mathrm{mM} \mathrm{NaHCO} 3$ - Sigma S5761, $3 \mathrm{mM}$ $\mathrm{KCl}$ - Sigma P5405, 0.1\% Sodium DL-lactate - Sigma L1375, $3 \mathrm{mM} \mathrm{CaCl}_{2}$ - Sigma C7902, $0.5 \mathrm{mM} \mathrm{MgCl}$ - Sigma M2393, $10 \mu \mathrm{g} / \mathrm{mL}$ Heparin sodium salt - Sigma H3149, 6g/L BSA, Sigma A6003, $0.02 \mathrm{mM}$ sodium pyruvate - Sigma P4562, $60 \mathrm{mg} / \mathrm{L}$ penicillin G sodium salt - Sigma P3032, $50 \mathrm{mg} / \mathrm{L}$ streptomycin sulfate - Sigma S9137, 4.10 $0^{-3} \mu \mathrm{M}$ epinephrine Sigma E4250, $0.2 \mu \mathrm{M}$ D-penicillamine - Sigma P4875, $0.1 \mu \mathrm{M}$ hypotaurine - Sigma H1384, 0.025\% phenol red - Sigma P3532). Putative zygotes were then distributed depending on culture conditions (Table 1).

\section{In vitro embryo development}

Twenty-four hours before starting the co-culture, all BOEC and VERO cells culture medium was changed by the embryo development medium (SOF Minitube 19990/0040, 5\% FCS - MP Biomedicals MP5418, 2\% BME amino acids solution - Sigma B6766, 1\% MEM non-essential amino acid solution - Sigma M7145, $3 \mathrm{mM}$ sodium pyruvate - Sigma P2256, 6g/L BSA, Sigma A6003) (Tervit et al. 1972). Putative zygotes were then placed within $500 \mu \mathrm{L}$ of culture medium without feeder cells (at $5 \% \mathrm{O}_{2}$ or at $20 \% \mathrm{O}_{2}$ ) or presence of feeders monolayers $\left(20 \% \mathrm{O}_{2}\right.$, BOEC or VERO) depending on culture conditions (Table 1 ) at $39^{\circ} \mathrm{C}$. Twenty-five putative zygotes were cultured into each well in 6 -well plates, without oil. $50 \%$ of medium was replaced every $48 \mathrm{~h}$ until day 8 where blastocyst stage was reached. 16-cell stage embryos were collected at $96 \mathrm{hpi}$. Blastocysts were collected at $192 \mathrm{hpi}$. Embryos were selected based on their morphology: at $96 \mathrm{hpi}$, only embryos with 15-20 observed cells were sampled (previously confirmed an analysis based on DAPI staining) and at $192 \mathrm{hpi}$, the presence of a blastocoel and a homogenous inner cell mass were evaluated before sampling. Embryos were washed twice in sterile PBS (BR0014G, Oxoid Limited, Basingstoke, 
Table 1 Experimental design for the culture of bovine embryos from the zygote to the blastocyst stage.

\begin{tabular}{llll}
\hline Name of culture condition & Feeder cell type & Embryo culture medium & Culture conditions \\
\hline $5 \%$ & None & Minitube SOF $+5 \%$ FBS $(25$ embryos $/ 500 \mu \mathrm{L})$ & $5 \% \mathrm{O}_{2}, 5 \% \mathrm{CO}_{2}, 90 \% \mathrm{~N}_{2}$ \\
$20 \%$ & & & $20 \% \mathrm{O}_{2}, 5 \% \mathrm{CO}_{2}$ \\
$20 \%+$ BOEC & BOEC & & \\
$20 \%+$ VERQ & VERO & & \\
\hline
\end{tabular}

UK) prior dry-freezing in $1.5 \mathrm{~mL}$ DNA LoBind RNAse-free Eppendorf (Sigma Z666548). They were stored at $-80^{\circ} \mathrm{C}$ for further RNA extraction experiments.

\section{RNA isolation}

For microarray experiments, total RNAs were extracted from batches of embryos ( $n=20$ of 16 -cell embryos and $n=10$ for day 8 blastocysts, four replicates per condition) using the PicoPure RNA extraction kit (Arcturus). A purification procedure using DNAse I (Qiagen) treatment at $25^{\circ} \mathrm{C}$ for $15 \mathrm{~min}$ was performed prior to elution. Total extracted RNAs were stored at $-80^{\circ} \mathrm{C}$ for further RNA labeling. Due to the little amount of RNA extracted, no quantification was possible.

Gene expression was evaluated by reverse transcription followed by real-time PCR as previously described (Peynot et al. 2015). Total RNA was extracted from batches of embryos $(n=30$ of embryos per stage, three replicates per condition) using the PicoPure RNA extraction kit (Arcturus). Prior to extraction, carrier RNA $(2.5 \mu$ g of $16 \mathrm{~S}-28 \mathrm{~S}$ carrier per sample - Roche Diagnostics) and an exogenous transcript (1 pg per embryo of luciferase mRNA - Promega) were added respectively to restrict RNA loss that occurs during column purification and estimate RNA recovery after purification. A DNAse I (Qiagen) treatment at $25^{\circ} \mathrm{C}$ for $15 \mathrm{~min}$ was performed prior to elution. Thanks to the evaluation of RNA quantity by Nanodrop, the number of 'equivalent embryos' in the sample after purification was calculated (Peynot et al. 2015).

\section{RNA labeling and microarray processing}

Transcriptional profiling was performed using a new custom bovine array for 16-cell embryos (GPL21724, AMADID: 066279) and its more recent update (GPL21734, AMADID: 075257) for blastocyst samples. These microarrays were designed based on bovine annotated Ensembl transcripts (http://www.ensembl.org/index.html, genome assembly UMD3.1) completed with NCBI specific transcripts defined as expressed in bovine embryo (Duranthon V. 2013 personal communication). For each transcript, two probes as different as possible were designed using Agilent software, eArray (https://earray.chem.agilent.com/earray/). The only difference between the two designs was represented by 14 probes corresponding to the exogenous luciferase transcripts and by 10 probes targeting endogenous retrovirus sequences, which had been previously published ( $\mathrm{Li}$ et al. 2014). In any case, these 24 probes were however excluded from our analyses. Both microarrays contained more than $97 \%$ of the bovine transcripts annotated in Ensembl data base (genome assembly UMD3.1).

Cyanine-3 (Cy-3) labeled cRNAs were prepared using $25 \mathrm{ng}$ of total RNA with the One-Color Low Input Quick Amp
Labeling kit (Agilent Technologies). Specific activities and cRNA yields were determined using the NanoDrop ND-1000 (Thermo Fisher Scientific).

As previously described (Jacquier et al. 2015), for each sample $600 \mathrm{ng}$ of Cy3 labeled cRNA (specific activity $>6.0 \mathrm{pmol}$ of $\mathrm{Cy} 3 / \mu \mathrm{g}$ of cRNA) were fragmented at $60^{\circ} \mathrm{C}$ for $30 \mathrm{~min}$ and then hybridized to the custom bovine arrays for $17 \mathrm{~h}$ at $65^{\circ} \mathrm{C}$ following the manufacturer's instructions (Agilent Technologies). After washing, slides were immediately scanned using G2565CA Scanner System (Agilent Technologies). The resulting images were analyzed with the Feature Extraction Software v10.7.3.1 (Agilent Technologies), using GE1_107_ Sep09 protocol. All the hybridization procedures were performed by CRB GADIE facility (INRA Jouy-en-Josas, France, http://crb-gadie.inra.fr/). The microarray data were submitted to the GEO database and the accession number GSE90473 was received.

Due to problems occurred along the labeling and/or hybridization, a few samples were excluded from the analysis. Here, 4 replicates for $5 \% \mathrm{O}_{2}, 3$ replicates for $20 \% \mathrm{O}_{2}, 3$ replicates for $20 \%+$ BOEC and 4 replicates for $20 \%+\mathrm{VERO}$ at 16-cell stage, and 3 replicates for $5 \% \mathrm{O}_{2}, 3$ replicates for $20 \% \mathrm{O}_{2}, 3$ replicates for $20 \%+$ BOEC and 4 replicates for $20 \%+$ VERO at day 8 blastocysts (Fig. 2) were analyzed.

\section{Reverse transcription and real-time PCR}

As previously described (Peynot et al. 2015), cDNAs were synthesized from total RNAs using the Superscript III enzyme (Invitrogen) and hexamer random primers (Roche Diagnostics) in $20 \mu \mathrm{L}$ final volume, following the manufacturer's instructions. Quantitative real-time PCR (qPCR) was carried out with SYBR Green PCR Master Mix (Applied Biosystems) and using a Step One Plus system (Applied Biosystems). Three technical replicates were performed for each sample and a standard curve protocol was used to evaluate gene expression. PCR reactions were performed on 0.1 or 0.5 equivalent embryos of cDNA per well in 96-well plates (4346907, Applied Biosystems), depending on the gene (Table 2). Primer sequences are provided in Table 2. To assess the amplification of the correct cDNA fragments, every amplicon was sequenced and blasted on NCBI RNA bovine data base. For each gene of interest, relative expression was normalized to the expression of two housekeeping genes, GAPDH and $Y W H A Z$, by using the qBasePLUS 2 software (Biogazelle, Gent, Belgium).

\section{Microarray analysis}

All the steps of microarray analysis was performed on $R$ Open statistical software (R: A language and environment for statistical computing - R Foundation for Statistical Computing, 


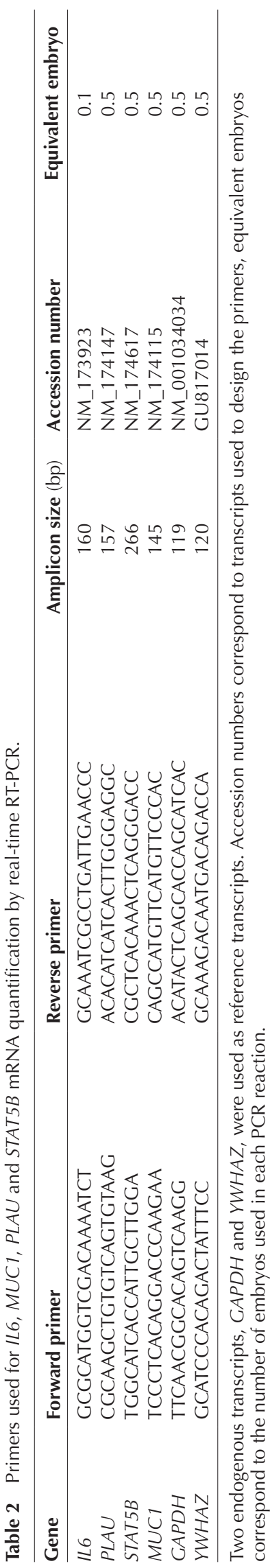

Vienna, Austria; 2012, R-Core-Team; http://www.r-project. org). Microarray data were first log2-transformed and then normalized by an inter-array median substraction. Descriptive analysis (hierarchical clustering analysis - HCA - and principal component analysis - PCA) were performed respectively with hclust and FactoMineR packages (Lê 2008). HCA was based on the Pearson correlation coefficient. Differentially expressed probes were evaluated using the Limma package (Linear Models for Microarray Data, Package R) (Smyth 2005). The $P$ values were corrected for multiple testing using the Benjamini-Hochberg method. In this study, the probes with an adjusted $P$ value $<0.05$ and a ratio $<0.5$ or $>2$ were selected as differentially expressed (DE). Finally, the significant DE genes with an annotated gene symbol were used to identify the impacted molecular and cellular functions and upstream regulators (cytokine, growth factor and transcription regulator) with Ingenuity Pathway Analysis (IPA, Ingenuity Systems, Mountain View, CA; http://www.ingenuity.com, build version: 377306M, content version: 27216297). Data were first submitted to core analysis and then compared by the IPA software. Results were presented according to calculated regulation score.

\section{Statistical analysis}

All statistical analyses were performed using the $R$ Open statistical software. Statistical analysis of development rates (cleavage, 16-cell stage and blastocyst) and gene expression were subjected to the Kruskal-Wallis test. Statistical differences (development rates and gene expression) between culture conditions were analyzed using Tukey's tests.

\section{Results \\ Development of bovine embryos according to oxygen rates and feeder cell presence}

To evaluate the impact of oxygen rates and of feeder cells on bovine early development, analysis focused on cleavage (48hi), 16-cell stage (96hpi) and day 8 blastocysts rates. A preliminary analysis of development kinetic was performed (data not shown) and revealed that the maximum number of 16-cell embryos was observed at $96 \mathrm{hpi}$ in all culture conditions.

No significant difference in cleavage rates (48 hpi) was observed between the different culture conditions (Fig. 1A). Similarly, no significant difference was observed between the culture conditions for the rates of 16-cell stage embryos at $96 \mathrm{hpi}$ (Fig. 1B). At $192 \mathrm{hpi}$ (Fig. 1C), culture of embryos at $20 \% \mathrm{O}_{2}$ without feeders significantly reduced day 8 blastocyst rate compared to the three other culture conditions.

\section{Comparison of transcriptome of 16-cell and blastocyst embryos obtained with different culture conditions}

Using a new custom bovine microarray (representing more than $97 \%$ of annotated transcripts from Ensembl 

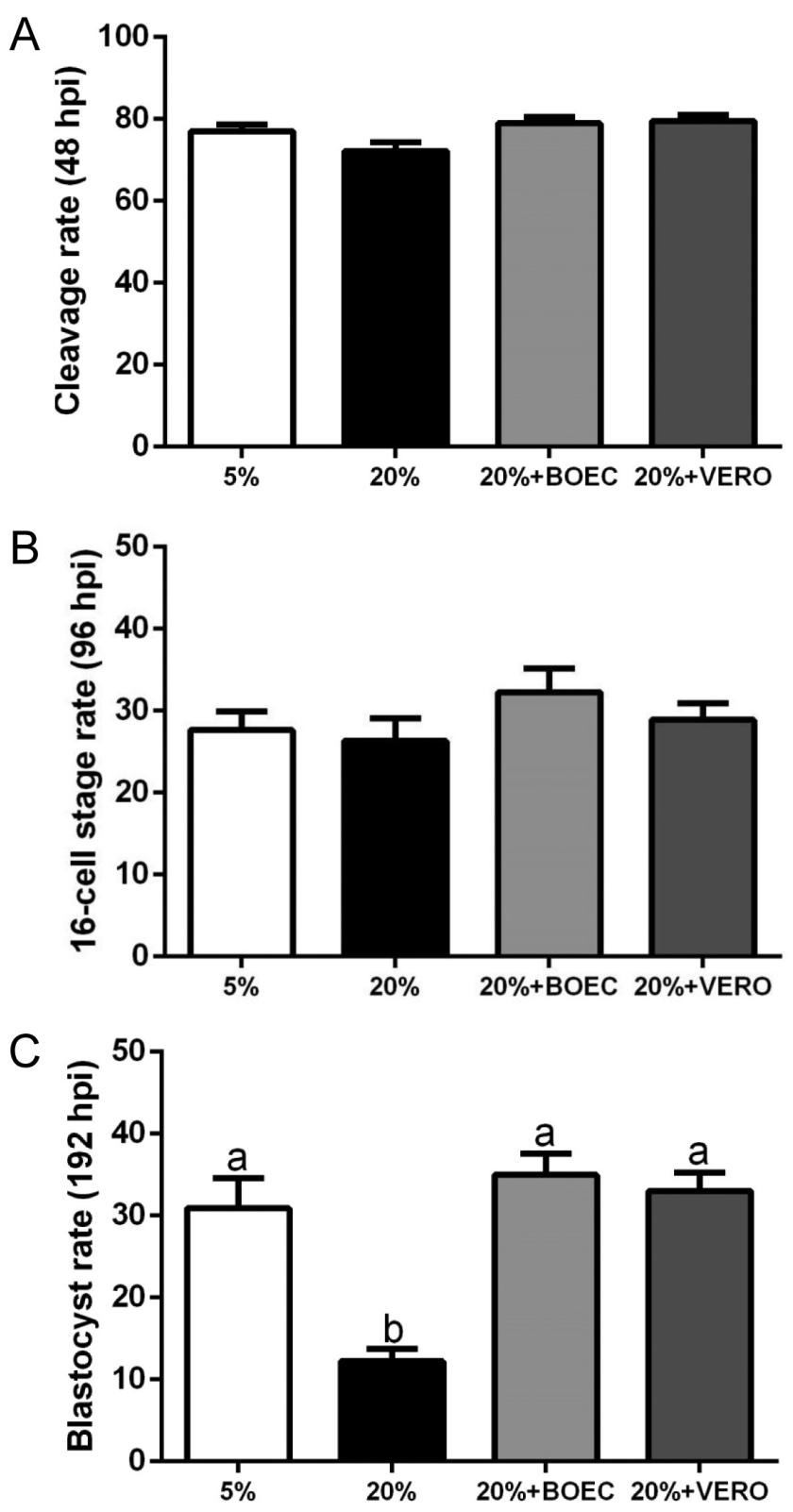

Figure 1 Development rates of bovine embryos at $5 \% \mathrm{O}_{2}, 20 \% \mathrm{O}_{2}$ or with co-culture systems. Rates were calculated on total putative zygotes put in culture. Data are the mean \pm S.E.M. (A) Cleavage rates of bovine embryos at $48 \mathrm{~h}$ post-insemination (hpi) with $5 \% \mathrm{O}_{2}(5 \%$, $n=31), 20 \% \mathrm{O}_{2}(20 \%, n=31), 20 \% \mathrm{O}_{2}+$ BOEC $(20 \%+\mathrm{BOEC}, n=30)$ and $20 \% \mathrm{O}_{2}+$ VERO $(20 \%+$ VERO, $n=22)$. No significant difference was revealed between the different culture conditions. (B) 16-cell stage rates of bovine embryos at $96 \mathrm{hpi}$ with $5 \% \mathrm{O}_{2}(5 \%, n=12)$, $20 \% \mathrm{O}_{2}(20 \%, n=13), 20 \% \mathrm{O}_{2}+$ BOEC $(20 \%+$ BOEC, $n=13)$ and $20 \% \mathrm{O}_{2}+$ VERO $(20 \%+$ VERO, $n=6)$. No significant statistical difference was revealed between the different culture conditions. (C) Day 8 blastocyst rates of bovine embryos at $192 \mathrm{hpi} \mathrm{with} 5 \% \mathrm{O}_{2}(5 \%$, $n=10), 20 \% \mathrm{O}_{2}(20 \%, n=20), 20 \% \mathrm{O}_{2}+\mathrm{BOEC}(20 \%+\mathrm{BOEC}, n=9)$ and $20 \% \mathrm{O}_{2}+$ VERO $(20 \%+$ VERO, $n=8)$. Different lowercase letters denote significant effects between culture conditions $\left(P\right.$ value $<10^{-7}$ or lower). genome assembly UMD3.1), the transcriptome of bovine embryos was analyzed at 16 -cell (96hpi) and at day 8 blastocyst stage (192 hpi) in the different culture conditions (Figs 2 and 3).

Hierarchical clustering revealed limited differences in embryo transcriptome between the four culture conditions at 16-cell and blastocyst stages, as shown by the very short clustering scale (Fig. 2). At the 16-cell stage, samples did not cluster according to culture conditions except for $20 \%+$ VERO samples. At the blastocyst stage, samples first clustered depending on the presence or absence of feeder cells, but no clustering according to oxygen rate or feeder cell type was observed. This close similarity between embryos cultured with different oxygen levels or on different feeder cells was confirmed by the small number of differential expressed (DE) probes (Fig. 3A), transcripts (Fig. 3B) and annotated genes (Fig. 3C).

Accordingly, very few DE transcripts (Fig. 3B) were detected between embryos cultured at 5\% $\mathrm{O}_{2}$ and $20 \%$ $\mathrm{O}_{2}$ at 16-cell and at day 8 blastocyst stages (respectively 1 and 36 transcripts). Also, a few DE transcripts were identified by the direct comparison of embryos cultured with the two different feeder cell types $(20 \%+$ BOEC vs $20 \%+$ VERO) at 16 -cell and day 8 blastocyst stages, respectively 14 and 10 transcripts (Fig. 3B). In contrast, feeder presence (BOEC or VERO) impacted more heavily the embryo transcriptome when compared to $20 \%$ $\mathrm{O}_{2}$ than to $5 \% \mathrm{O}_{2}$ at both stages (Fig. 3B). Moreover, according to the number of DE transcripts, the major impact of feeder presence was found at day 8 blastocyst stage (Fig. 3B).

To analyze whether the two feeder cell types affected the same transcripts, DE transcripts identified between each co-culture systems to a single oxygen concentration control condition were compared (Fig. 4). These comparisons revealed that although some DE transcripts were impacted by both co-culture systems, others were specifically regulated by BOEC or VERO presence. Nevertheless, when a DE transcript was identified as impacted by both co-culture systems, its regulation was similar by both feeder cell types (data not shown).

\section{Overview of molecular and cellular functions regulated by the presence of feeder cells and their cell types}

To identify the molecular and cellular functions regulated by the presence of feeder cells and by feeder cell types, DE genes (Fig. 3C) were submitted to IPA software analysis (Fig. 5). Among all identified molecular and cellular functions with a $P$ value $<0.05$, we focused our analysis on the top 15 biological functions identified as differentially regulated between two culture conditions (Fig. 5). All data are available in Supplementary Table 1 (See section on Supplementary data provided at the end of the article). 


\section{6-cell embryos (96 hpi)}

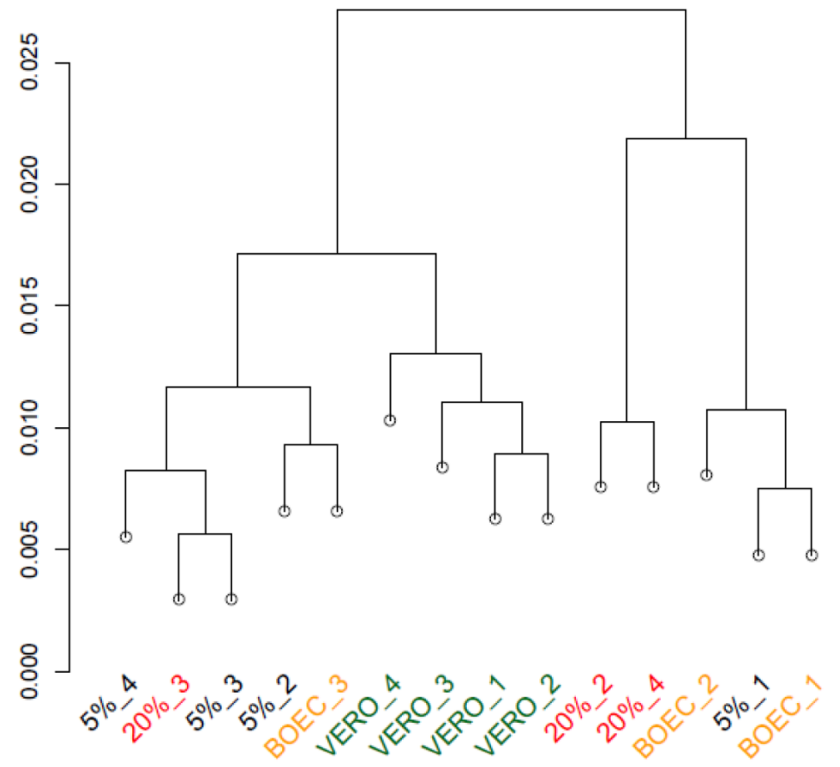

day 8 blastocysts (192 hpi)

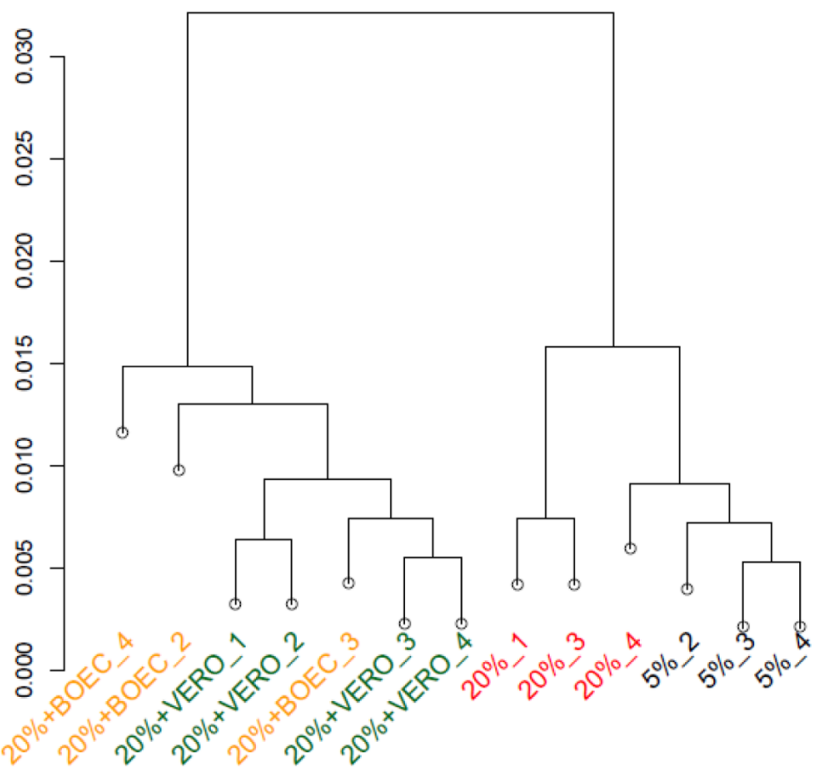

Figure 2 Hierarchical clustering of transcriptomes of 16-cell and blastocyst embryos cultured with or without co-culture systems. Hierarchical clustering was based on the Pearson correlation coefficient of 16-cell embryos (96 hpi) transcriptome at $5 \% \mathrm{O}_{2}(5 \%, n=4 \mathrm{samples}), 20 \% \mathrm{O} 2$ $(20 \%, n=3), 20 \% \mathrm{O}_{2}+$ BOEC $(20 \%+$ BOEC,$n=3)$ and $20 \% \mathrm{O}_{2}+$ VERO $(20 \%+$ VERO, $n=4)$ and of day 8 blastocyst transcriptome (192 hpi) at $5 \% \mathrm{O}_{2}(5 \%, n=3), 20 \% \mathrm{O}_{2}(20 \%, n=3), 20 \% \mathrm{O}_{2}+$ BOEC $(20 \%+$ BOEC,$n=3)$ and $20 \% \mathrm{O}_{2}+$ VERO $(20 \%+\mathrm{VERO}, n=4)$.

First of all, due to the very small number of DE genes between embryos cultured with different oxygen levels $\left(5 \%\right.$ or $20 \% \mathrm{O}_{2}$ ) in the absence of feeder cells (Fig. 3C), no biological function could be identified as regulated at 16-cell stage and very few appeared to be impacted by the oxygen tension level at the blastocyst stage (Fig. 5). Among our selection of top 15 impacted biological functions in all comparisons, only the 'proliferation of cells' has been marginally upregulated in blastocyst cultured at $5 \% \mathrm{O}_{2}$ when compared to blastocyst cultured at $20 \% \mathrm{O}_{2}$.

For the same reason, very few molecular and cellular functions were identified as weakly regulated in the direct comparison between the two co-culture systems at 16 cell stage (Fig. 5): 'migration of cells' and 'apoptosis' tended to be upregulated by the presence of VERO, whereas 'proliferation of cells' and 'invasion of cells' tended to be upregulated in BOEC co-culture system. Interestingly, at the blastocyst stage, none of these functions were differentially regulated.

In the 16-cell embryos (Fig. 5), the presence of feeder cell mainly induced the upregulation of biological functions relative to cell movement ('cell movement', 'migration of cells', 'invasion of cells', 'chemotaxis of cells') and downregulated those relative to the 'synthesis of reactive oxygen species', without distinction of the origin of feeder cells. Interestingly, only the comparison between the absence of feeder cell at $20 \% \mathrm{O}_{2}$ and the co-culture system using VERO showed the reduction of the cell viability and the induction of the apoptosis by the presence of VERO.

At the blastocyst stage (Fig. 5), more molecular and cellular functions appeared to be regulated. The cell viability ('cell viability', 'cell survival', 'proliferation of cells' and 'viability of tumor cells') was repressed by the presence of feeder cells without distinction of feeder cells origin. Consequently, the apoptosis was upregulated in blastocyst cultured in co-culture systems. The functions relative to cell movement ('cell movement' and 'migration of cells') appeared to be downregulated by the presence of both feeders except when the presence of VERO cell was compared to $20 \% \mathrm{O}_{2}$. The presence of feeders also reduced the differentiation of cells. Additionally, feeder cells influenced the 'fatty acid metabolism' of blastocyst, but with a different pattern according to their origin. Indeed, BOEC reduced the fatty acid metabolism whereas the presence of VERO upregulated it.

\section{Putative activation of transcription factors implicated in bovine early development}

Transcription factors are crucial elements of signaling pathways and therefore also of the regulation of cellular biological functions. For this reason, using IPA software analysis, the putative upstream regulators with regulated activity in the different comparisons of our experimental system were identified starting from the DE genes (Fig. 3C) and consequently, the implication 
16-cell embryos (96 hpi)
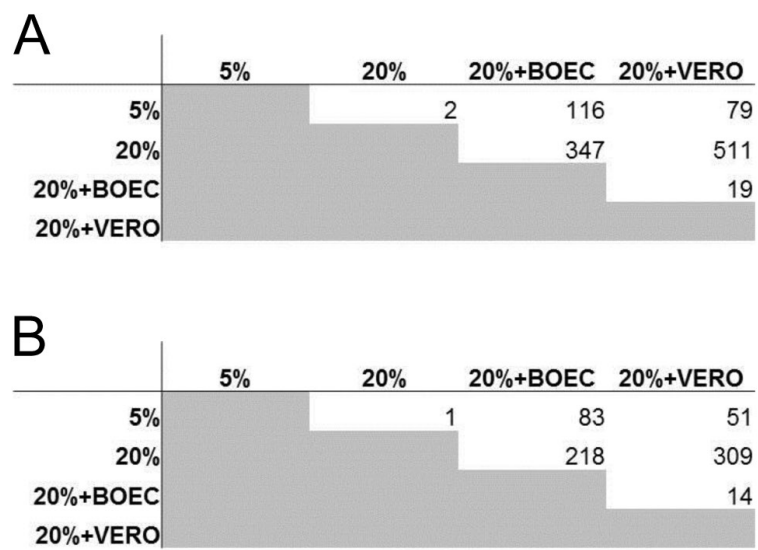

C

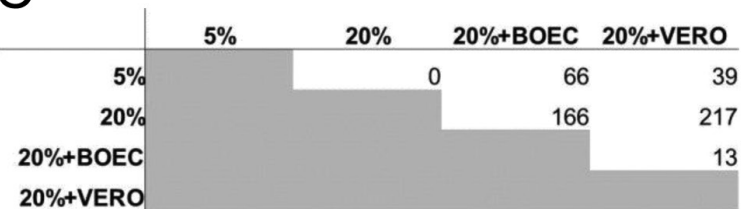

\section{day 8 blastocysts (192 hpi)}
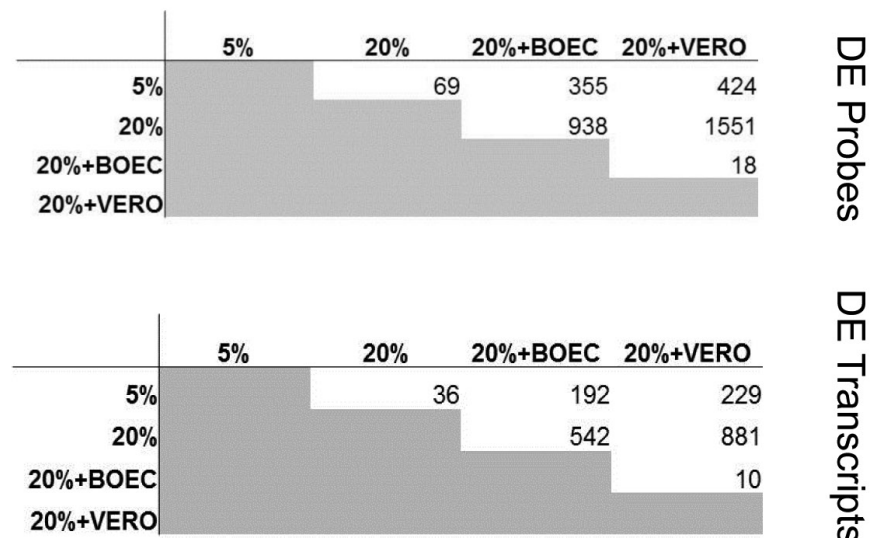

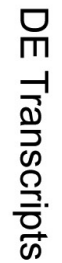

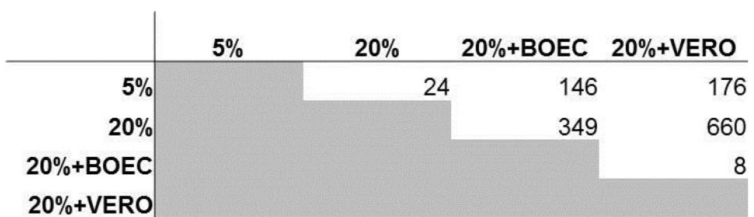

Figure 3 Comparison of transcriptomes of 16-cell and blastocyst embryos cultured with or without co-culture systems. 16-cell (96hpi) and day 8 blastocyst (192 hpi) embryos were obtained at $5 \% \mathrm{O}_{2}, 20 \% \mathrm{O}_{2}$ or in presence of feeder cells $\left(20 \% \mathrm{O}_{2}\right.$, BOEC or VERO) and their transcriptome was analyzed by microarray. (A) Number of differentially expressed (DE) probes, (B) DE transcripts and (C) DE annotated genes between embryos obtained at $5 \% \mathrm{O}_{2}, 20 \% \mathrm{O}_{2}, 20 \% \mathrm{O}_{2}+$ BOEC and 20\% $\mathrm{O}_{2}+$ VERO at 16-cell (96 hpi) and day 8 blastocyst (192 hpi) stages (adjusted $P$ value $<0.05$ and ratio $<0.5$ or $>2$ ).

of transcription factors was evaluated (Fig. 6A). Among all the identified transcription factors with a $P$ value $<0.05$, we focused our analysis on the top 15 factors in terms of regulation (Fig. 6A). All data are available on in Supplementary Table 2.

As previously observed, due to the reduced quantity of DE genes between the two oxygen conditions and between the two co-culture systems at both analyzed developmental stages, no transcription factors were identified as regulated by the oxygen level or by the origin of feeder cells (Fig. 6A). In this way, only the comparison of embryos cultured with and without feeder cells enable to detect some transcription factors with a regulated activity.

In 16-cell embryos, few transcription factors presented a regulated activity. NFkB and JUN activity appeared upregulated by the presence of both feeder cell types when compared to both oxygen levels culture conditions whereas the MYC activity was downregulated by both co-culture systems only when 16-cell embryos

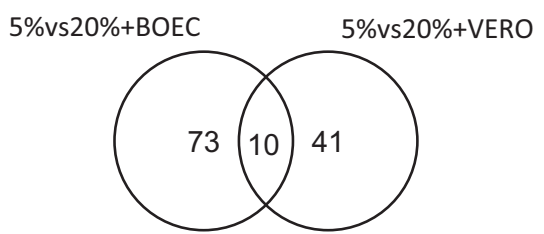

$20 \%$ vs $20 \%+B O E C$

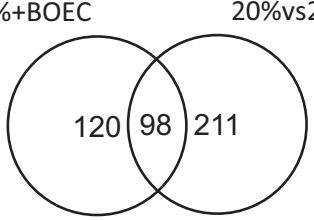

Day 8 blastocysts

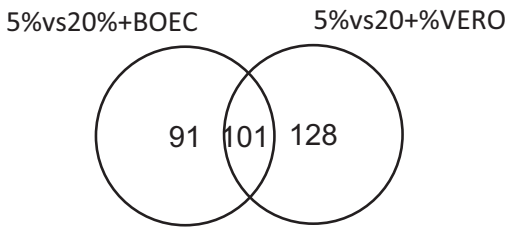

$20 \%$ vs $20 \%+B O E C$

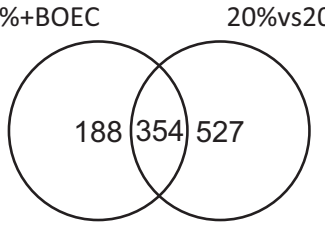

Figure 4 Differentially expressed transcripts of 16-cell and blastocyst embryos cultured with or without co-culture systems. 16-cell (96 hpi) and day 8 blastocyst (192 hpi) embryos were cultured in presence of the two different feeder cell types $\left(20 \% \mathrm{O}_{2}\right.$, BOEC or VERO) according to oxygen control conditions (5\% of $20 \% \mathrm{O}_{2}$ ). Differentially expressed transcripts were defined with adjusted $P$ value $<0.05$ and ratio $<0.5$ or $>2$. 


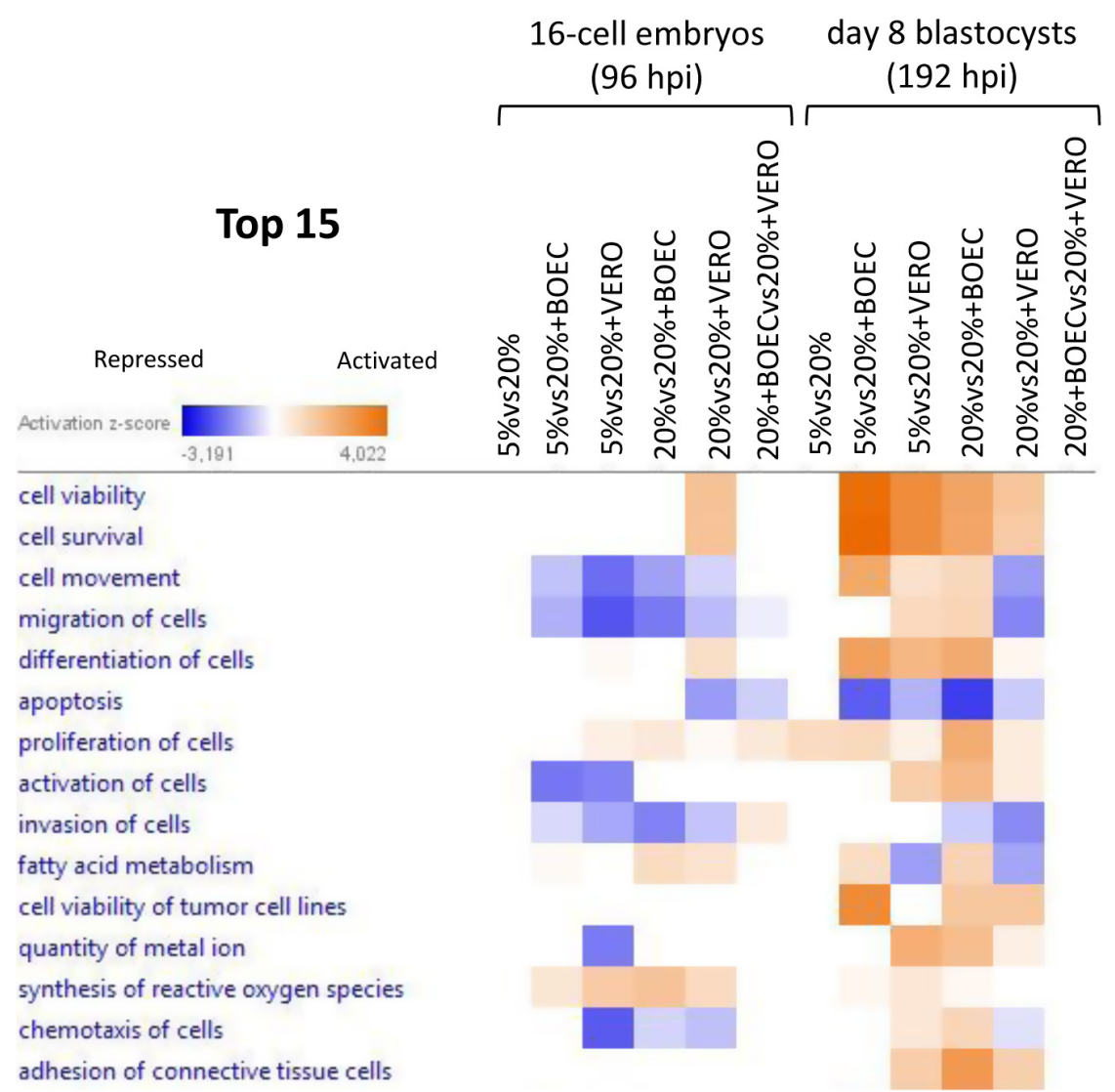

Figure 5 Impacted molecular and cellular functions in 16-cell and blastocysts cultured with or without co-culture systems. Predicted activation of molecular and cellular functions impacted in 16-cell (96 hpi) and day 8 blastocyst (192 hpi) embryos cultured in presence of the two different feeder cell types $\left(20 \% \mathrm{O}_{2}\right.$, BOEC or VERO) according to oxygen control conditions ( $5 \%$ of $20 \% \mathrm{O}_{2}$ ) was analyzed using ingenuity pathway analysis based on DE annotated genes. DE genes were defined with adjusted $P$ value $<0.05$ and ratio $<0.5$ or $>2$. Only the 15 most impacted molecular and cellular functions are presented ( $P$ value $<0.05$ ). Orange squares correspond to activated functions in the first condition of the comparison indicated at the top of the column, whereas blue squares correspond to inhibited functions. Color intensity is correlated to activation score: the stronger the color is, the more important the activation score is. compared to embryos cultured at $5 \% \mathrm{O}_{2}$. Interestingly, the comparison of presence and absence of feeders at $20 \% \mathrm{O}_{2}$ identified more transcription factors with regulated activity: BRCA1, SP1 as downregulated by BOEC and VERO or CEBPB, CBX5 as upregulated by feeder cells.

At the blastocyst stage, many more transcription factors with a regulated activity were identified. Interestingly, most of them presented no difference of activation according to feeder cell origin, such as: STAT3, BRCA1, CEBPB, SP1, EGR1 which were downregulated by the presence of feeder cells when compared to both oxygen levels whereas NFkB and STAT5B were both impacted by the two co-culture systems, downregulated when compared to $5 \% \mathrm{O}_{2}$ and upregulated when compared to $20 \% \mathrm{O}_{2}$.

\section{Identification of putative cytokines and growth factors secreted by feeders and implicated in bovine early development}

Based on DE genes (Fig. 3C), putative upstream regulators secreted by feeders were identified using the IPA software. Among all the determined upstream regulators, we focused our analysis on the top 15 of cytokines and growth factors in terms of regulation of their downstream pathways (Fig. 6B). All data are available in Supplementary Table 3.
As previously discussed, due to the small number of DE genes identified between the two oxygen culture conditions, no putative upstream regulators were identified, suggesting no differential secretion of embryonic cytokines and growth factors induced by high oxygen level at both developmental stages. The comparison between the two co-culture systems revealed only the differential regulation of the TNF signaling pathway which appeared to be upregulated by the presence of BOEC in 16-cell embryos.

Most of the identified cytokine and growth factors at 16-cell stage appeared putatively secreted by both feeder cells, such as OSM, IL1B, IL13, IL1A, IGF1, EGF. Even if some were identified, they were differentially regulated when compared to $5 \% \mathrm{O}_{2}$ or to $20 \% \mathrm{O}_{2}$ (for instance, TGFB1, VEGF, AGT, FGF2, IFNG, TNF, HGF), none presented a differential implication according to feeder origin.

At the blastocyst stage, few of these regulators appeared to be upregulated by feeder presence, such as OSM and IFNG, when compared to both oxygen culture conditions. Instead, others appeared to be downregulated by the presence of feeder cells, for instance, TGFB1, SPP1, FGF2 and IL1A. In other cases, the regulation observed at the 16-cell stage was enhanced at the blastocyst stage, like it happened for VEGF and AGT. Moreover, the GDF2 signaling pathway was identified as being downregulated by the presence 
A

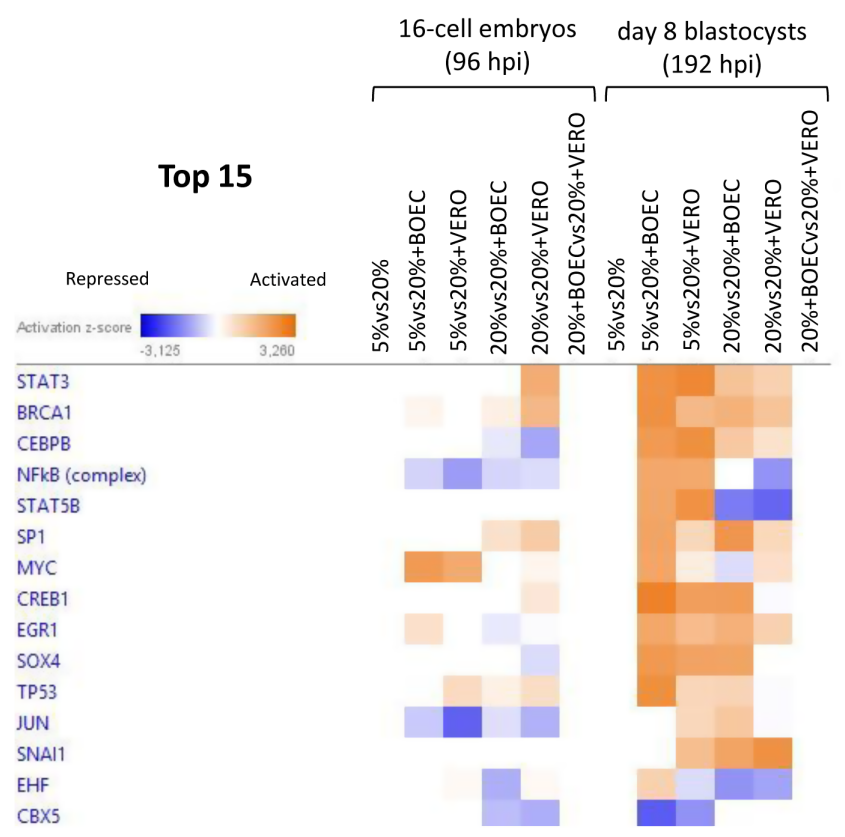

B

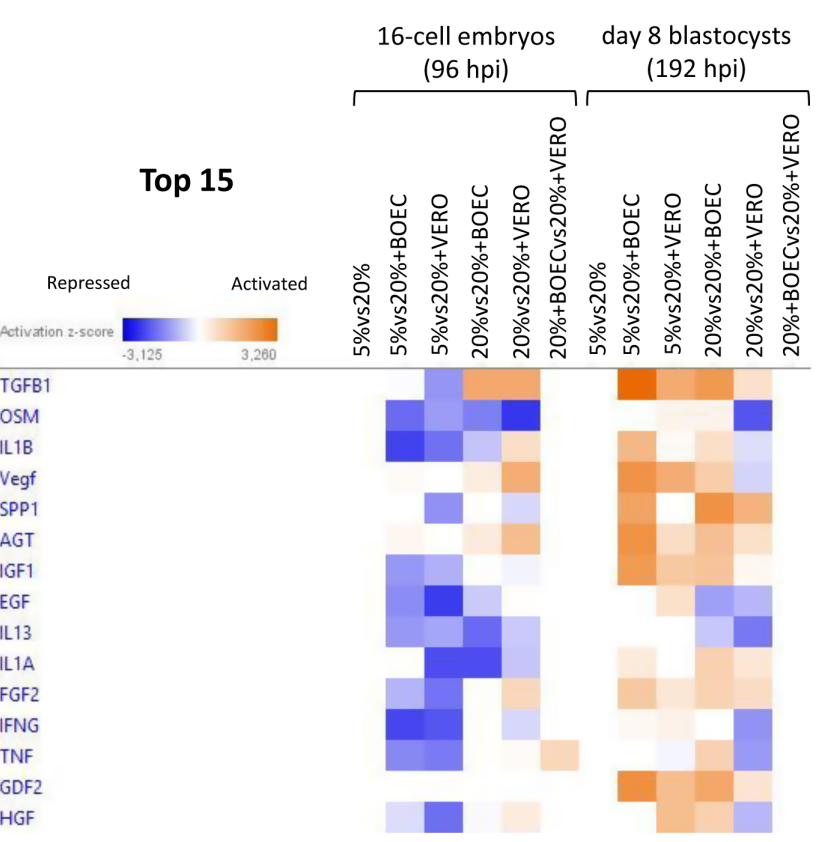

Figure 6 Upstream regulators involved in the regulation of embryo physiology at 16-cell and blastocyst stages. Upstream regulators predicted were defined as presenting regulated signaling pathways at 16 -cell $(96 \mathrm{hpi})$ and day 8 blastocyst $(192 \mathrm{hpi})$ embryos cultured in presence of the two different feeder cell types $\left(20 \% \mathrm{O}_{2}\right.$, BOEC or VERO) according to oxygen control conditions $\left(5 \%\right.$ of $\left.20 \% \mathrm{O}_{2}\right)$. Analysis made using the ingenuity pathway analysis based on DE annotated genes were defined with adjusted $P$ value $<0.05$ and ratio $<0.5$ or $>2$. (A) Selection of the 15 most impacted transcription factors signaling pathways ( $P$ value $<0.05$ ). (B) Selection of the 15 most impacted signaling pathways relative to cytokines or growth factors ( $P$ value $<0.05$ ). Orange squares correspond to activated upstream regulators in the first condition of the comparison indicated at the top of the column, whereas blue squares correspond to inhibited upstream regulators. Color intensity is correlated to activation score: the stronger the color is, the more important the activation score is.

of feeders only at blastocyst stages. For all these regulators, no important differential impact according to feeder origin was observed.

\section{Impact of oxygen levels and origin of feeder cells on IL6, MUC1, STAT5B and PLAU expression}

Since co-culture systems are known to regulate cell survival and apoptosis pathways in embryos (Carnegie et al. 1997, Menck et al. 1997, Cordova et al. 2014, Schmaltz-Panneau et al. 2014, 2015), among the DE genes (Fig. 3C), we selected four genes (ILG, PLAU, MUC1, STAT5B) which had been identified through IPA analysis (Fig. 5) and which were involved in these functions. Moreover, IL6 and STAT5B were also identified as involved in fatty acid metabolism and IL6, PLAU and MUC1 as implicated in synthesis of reactive oxygen species by IPA analysis. As most of these functions appeared to have more impact at the blastocyst stage than at the 16-cell stage, we focused the analyses of their relative expression at the blastocyst stage.

RT-qPCR assays (Fig. 7) revealed a significant increase of IL6 expression in blastocyst cultured at $20 \% \mathrm{O}_{2}$ when compared to blastocyst culture at $5 \% \mathrm{O}_{2}$. The presence of BOEC induced no differential expression of IL6 when compared to $5 \% \mathrm{O}_{2}$ but a reduction of IL6 was observed when compared to $20 \% \mathrm{O}_{2}$. In blastocysts cultured with VERO, the IL6 expression could not be determined using RT-qPCR, thus, the expression of IL6 mRNA was significantly decreased compared to other culture conditions. The increase in oxygen level induced a significant decrease of MUC1 mRNA level. Moreover, both co-culture systems not only significantly counteracted this decrease in MUC1 expression but also resulted in a significant increase in MUC1 expression when compared to both culture conditions without feeders (5\% and $20 \% \mathrm{O}_{2}$ tension). Culture of embryos at $20 \% \mathrm{O}_{2}$ without feeders induced a decrease in PLAU expression at the blastocyst stage when compared to $5 \%$ $\mathrm{O}_{2}$. Nevertheless, the presence of co-culture systems (based on BOEC or VERO) re-established PLAU mRNA levels, with a significant increase when compared to $20 \% \mathrm{O}_{2}$ and no differential expression when compared to $5 \% \mathrm{O}_{2}$. No influence of oxygen tension was observed on STAT5B mRNA level whereas both co-culture systems induced a significant decrease of STAT5B expression when compared to culture without feeders (at $5 \%$ and $20 \% \mathrm{O}_{2}$ ).

Collectively, the expression patterns of these four DE genes observed by microarray or RT-qPCR were very close. 

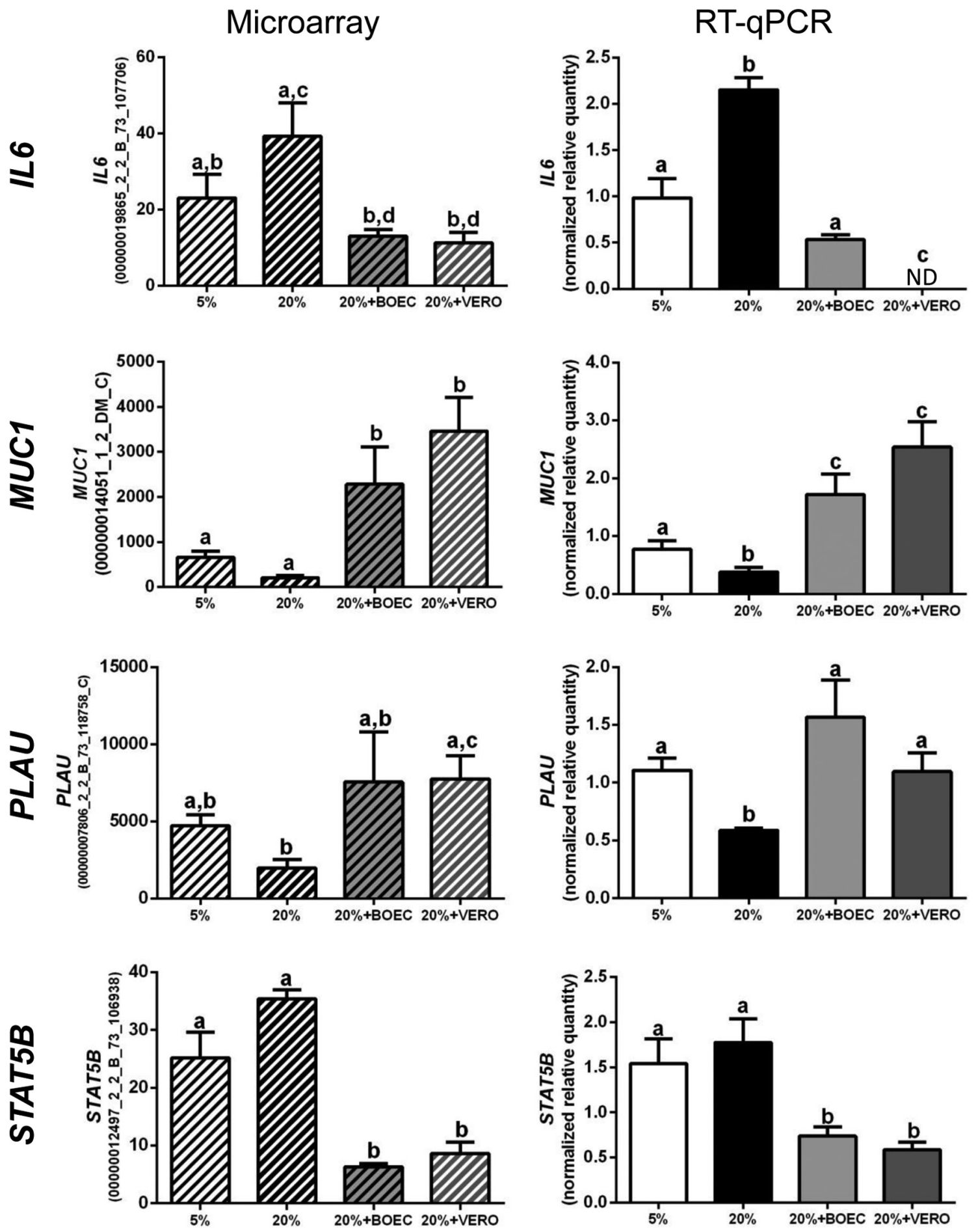

Figure 7 Expression of IL6, MUC1, PLAU, STAT5B in day 8 blastocysts. Expressions were analyzed by microarray (left column) and RT-qPCR (right column) in day 8 blastocysts (192 hpi). Microarray data were first log2-transformed and then normalized by an intra-array median substraction. Relative expression of genes obtained by RT-qPCR was normalized by the expression of two housekeeping genes, GAPDH and YWHAZ. Bars are representative of the mean value \pm S.E.M. Different lowercase letters denote significant differences between culture conditions $(P$ value $<0.05$ or lower). ND: Not Detected.

\section{Discussion}

The aim of this study was to investigate the impact of co-culture systems in the SOF medium on bovine embryo physiology by analyzing the influence of BOEC or VERO cells on bovine embryo transcriptome during early development. To the best of our knowledge, our study is the first one to provide high-throughput 
data about the impact of co-culture systems on embryo transcriptome.

First of all, the comparison of the early development of bovine embryos cultured without feeders in high or low oxygen level ( $20 \%$ vs $5 \%$ ) revealed no impact of the oxygen level on cleavage and 16-cell embryos rates, whereas the proportion of blastocysts was significantly reduced at $20 \% \mathrm{O}_{2}$. This confirms the deleterious effect of high oxygen level on embryo development previously observed starting at 8/16-cell stage in various culture medium (Watson et al. 1994, Rizos et al. 2001, Amin et al. 2014) including in SOF medium (Takahashi et al. 2000, Yuan et al. 2003, Rho et al. 2007, Schmaltz-Panneau et al. 2015). The analysis of embryo transcriptomes revealed a very limited impact of high oxygen level at 16-cell and blastocyst stages, with respectively 1 and 36 DE transcripts. Interestingly, none of the oxygen regulated transcripts evidenced by Amin and coworkers or Rho and coworkers at 8/16cell and blastocyst stages are included in DE transcripts in our analysis with an adjusted $P$ value of 0.05 and ratio $<0.5$ or $>2$ (Rho et al. 2007, Amin et al. 2014). This difference may be due to the embryo culture systems used in these analyses, which differed in terms of culture medium, medium volume, proportion and origin of sera. In fact, the culture medium was shown to influence embryonic gene expression during in vitro culture (Sagirkaya et al. 2006). Moreover, our selection of blastocysts based on morphology may have reduced the number of genes found impacted by oxidative stress. Furthermore, our data revealed a predicted activation of the proliferation of cells in blastocysts cultured at $5 \%$ $\mathrm{O}_{2}$ when compared to the ones cultured at $20 \% \mathrm{O}_{2}$. This was consistent with previous reports of an increase in total cell number in embryos cultured at $5 \% \mathrm{O}_{2}$ in SOF medium at the morula stage when compared to $20 \% \mathrm{O}_{2}$ culture condition (Lequarre et al. 2003, Yuan et al. 2003). Moreover, oxidative tension is known to increase the length of the fourth cell cycle in bovine embryo in SOF medium (Lequarre et al. 2003). As a consequence, blastocysts obtained at $20 \% \mathrm{O}_{2}$ could have a lower total number of cells due to an increase in the cell cycle length and therefore a decrease in cell proliferation. Collectively, these results suggest that, in our system, the blastocysts obtained at $20 \% \mathrm{O}_{2}$ present lower cell number, which has been previously described (Schmaltz-Panneau et al. 2015), and are able to resist to oxidative stress with a little intervention of free radical scavenging. Furthermore, the presence of pyruvate and citrate in SOF medium may be involved in the protection of embryos from free radical injury induced by culture with high oxygen level (Rho et al. 2007). Thus, blastocysts with lower total cell number could be selected because of pyruvate and citrate levels present in SOF medium which could be involved in the protection of embryos with lower cell number to oxidative stress.
At the difference of a large majority of BOEC co-culture systems, our analysis is the first using frozen BOEC. Compared to previous studies, no difference of developmental rates and kinetic was observed (Fig. 1) (Cordova et al. 2014, Schmaltz-Panneau et al. 2014, 2015). Moreover, no impact in BOEC monolayer morphology was evidenced (data not shown). Thus, the use of frozen preparation of BOEC could be an alternative to fresh BOEC monolayer cultures.

Our data are the first using VERO co-culture system in SOF medium. However, our cleavage, 16-cell and blastocyst rates are comparable to previous studies (Menck et al. 1997, Pegoraro et al. 1998) suggesting total compatibility of SOF medium with VERO co-culture system.

The comparison of BOEC and VERO co-culture systems revealed no significant difference of kinetic and rates of development at 48 (2-cell stage), 96 (16-cell stage) and 192 (day 8 blastocyst) hpi (Fig. 1). Although culture media differ, these data are consistent with previously published ones (Menck et al. 1997, Pegoraro et al. 1998), confirming an equivalent impact of both feeder cell types in terms of kinetic and developmental rates.

The analysis of embryo transcriptome cultured with BOEC orVERO by hierarchical clustering (Fig. 2) revealed a very similar impact of both feeder cells on embryo gene expression, confirmed by the few transcripts identified as DE between the two co-culture systems at 16-cell (92 hpi) and blastocyst (192 hpi) stages, respectively 14 and 10 DE transcripts (Fig. 3). Indeed correlation clustering showed a relative homogenization of 16-cell embryo transcriptomes by VERO cells leading to the co-segregation of the four $20 \%+V E R O$ samples. On the other hand, other conditions appeared intermixed, which could suggest a high 'glucose-condition' variability. At the blastocyst stage, segregation of samples with culture conditions is more pronounced but mainly opposed 'co-culture' to 'without co-culture' samples. In each of these two sub-groups, the absence of clear segregation of samples with precise culture condition may suggest again a high intra-condition variability. This could be linked to the variability of origin of BOEC batches which could influence the timing of de-differentiation during culture previously observed (Schmaltz-Panneau et al. 2015). Concerning VERO cells, these results also suggest a slightly different evolution between cultures sessions. Whatever the case, it is necessary to underline that, at one specific stage, samples are very similar whatever the culture condition: an idea of this proximity is given by a hierarchical clustering including all the samples at both stages (Add. File 4). Compared to the interstage differences, the variations we are looking at between culture conditions at one stage are really tiny.

Moreover, the predicted biological functions defined as marginally regulated by the origin of feeder at 16 -cell stage (relative to migration of cells, apoptosis and proliferation) are not identified at blastocyst stage, 
suggesting a transient differential regulation of embryo physiology during the earlier stages of bovine early development. Thus, the feeder origin does not impact the development rate and the embryo physiology at the blastocyst stage. Furthermore, no differential upstream regulators (Fig. 6) were identified as preferentially involved in the regulation of embryo physiology by one of the feeders, suggesting no difference in feeder secretomes regardless of their origin. This observation could be related to the partial de-differentiation of BOEC observed during their monolayer culture (SchmaltzPanneau et al. 2015), suggesting the loss of their oviductal specificity. Maintaining the 3D conformation of BOEC using vesicles (Lopera-Vasquez et al. 2016) or suspension (Rottmayer et al. 2006) may maintain the BOEC secretion closer to the ones observed in vivo. Comparative analysis of secretomes from oviduct, BOEC and VERO could be helpful to identify the factors specifically secreted by the oviduct cells and thus to choose the best in vitro system to study oviduct/embryo cross-talk.

Compared to the embryos cultured in SOF medium at $5 \% \mathrm{O}_{2}$, none of the tested co-culture systems influence the developmental kinetic (data not shown) or rate (Fig. 1): same cleavage, 16-cell and blastocyst rates were observed at $5 \% \mathrm{O}_{2}$ or in presence of feeder cells (BOEC or VERO). These data disagree with the ones previously published in which the proportion of blastocysts obtained with BOEC is higher than that in $5 \% \mathrm{O}_{2}$ in SOF medium (Schmaltz-Panneau et al. 2015). This difference is certainly relative to the higher proportion of blastocyst obtained at $5 \% \mathrm{O}_{2}$ in our analysis. Moreover, since the exact composition of commercial Minitube SOF is not available, a difference of composition when compared to home-prepared SOF used by Schmaltz-Panneau and coworkers cannot be excluded (Rottmayer et al. 2006; Schmaltz-Panneau et al. 2015). Furthermore, other differences of media components used in our whole in vitro maturation/fertilization/culture procedure can be reported (such as the presence of EGF, FGF and IGF1 in maturation medium) and may influence oocyte quality and thus embryo development. Moreover, Takahashi et al. (1996) did not report a benefice of BOEC presence on blastocyst development in other culture conditions $\left(\mathrm{TCM} 199+5 \% \mathrm{O}_{2}\right)$ (Rieger et al. 1995). Thus, the influence of BOEC on developmental rates seems to be dependent on the composition of culture medium.

Interestingly, the qualitative analysis of embryo transcriptomes by hierarchical clustering (Fig. 2) gathered samples from embryos derived with or without co-culture systems only at the blastocyst stage, thus revealing the presence of feeder cells influence embryo gene expression regardless of the origin of feeder. The analysis of DE transcripts (Fig. 3) revealed that embryos (16-cell embryos and blastocysts) cultured in co-culture systems are closer to embryos derived at $5 \% \mathrm{O}_{2}$ than that at $20 \% \mathrm{O}_{2}$, suggesting few differences between embryos cultured at $5 \% \mathrm{O}_{2}$ and the ones cultured in presence of feeder cells. Moreover, whatever is the stage, the DE transcripts revealed by the presence of a feeder cell type to culture system without feeders (Fig. 4) has shown that both feeder cells partly regulate the expression of the same genes. This is consistent with our previous observation of no important difference between co-culture systems. This also suggests that both feeder cells partly affect the same pathways to regulate embryo physiology. To reinforce this, the analysis of regulated biological functions in embryos revealed first that functions identified at 16-cell stage are transiently regulated and then that both co-culture systems mostly influence in the same manner as the biological pathways (Fig. 5). Apparently, BOEC and VERO seemed to reduce the cell survival, the migration of cells and the differentiation of cells activity and increase the apoptosis in blastocyst. Only the fatty acid metabolism appeared to be differentially impacted by feeder cells origin: it was downregulated by BOEC and upregulated by VERO. These data are consistent with the previous observations made on feeder involvement on mammalian early development, namely the secretion of embryotrophic factors implicated in the cell cycle and the metabolism of the embryo (Ouhibi et al. 1989, Bavister 1995, Lai et al. 1996a, Menck et al. 1997, Duszewska et al. 2000, Schmaltz-Panneau et al. 2014, 2015). Moreover, these data reinforce the idea that the influence of co-culture system is not specific to any particular cell origin, as suggested by Lai and coworkers (Lai et al. 1996a). Nevertheless, these previous works suggest an increase in embryo quality especially through an improvement of total cell number of blastocysts by the presence of feeder cells. But our data suggest the opposite with the increase of apoptosis activity in blastocyst cultured with BOEC or VERO, which could partially explain, with at least the extension of cell cycle length previously described, the decrease of total cell number that could be observed in blastocyst cultured with feeders. Moreover, the presence of feeder cells in co-culture systems may reduce glucose concentration necessary to embryo development since 8-16-cell stage (Lequarre et al. 1997). However, no signaling pathways relative to glucose metabolism can be observed as importantly impacted by the presence of feeder cells (Fig. 2 and Supplementary Figure 1). Thus, the increase of apoptosis in embryo cultured with BOEC or VERO is probably not due to a nutrient lack for embryo development.

As observed with the regulated biological functions, both co-culture systems influence the same transcription factors. The regulated transcription factors identified at the 16-cell stage were not revealed at the blastocyst stage and thus are transiently affected. Interestingly, at the blastocyst stage, the two co-culture systems (BOEC or VERO) influence in the same manner the same transcription factors identified as regulated (Fig. 6A). For example, they repressed the activity of two members of STAT family, i.e. STAT3 and STAT5B. STAT factors are 
involved in signaling pathways of numerous cytokines to regulate growth and differentiation of mammalian cells (Maj \& Chelmonska-Soyta 2007). STAT3 activation in bovine blastocyst is associated to ICM differentiation (Meng et al. 2015) but also improves cell survival and reduces apoptosis in mouse embryo (Shen et al. 2009). STAT5B activation in murine blastocyst is also associated to ICM differentiation (Nakasato et al. 2006). In addition to its predicted downregulated activity, STAT5B expression decreases in presence of feeder cells (BOEC or VERO, Fig. 7). This reinforces the downregulation of STAT5B activity when compared to $5 \% \mathrm{O}_{2}$. Indeed, STAT activity as transcription regulators implicates their activation by post-translational modifications, such as phosphorylation (Maj \& Chelmonska-Soyta 2007). With the reduction of STAT5B mRNA level, the quantity of STAT5B protein potentially activated is also reduced. Consequently, the decrease in the activation and expression of these STAT factors certainly contribute to a decrease in the cellular cycle and differentiation revealed by the IPA analysis of DE genes.

To regulate these transcription factors, feeder cells secrete various factors including numerous growth factors and cytokines (Gandolfi \& Moor 1987, Mermillod et al. 1993, Lai et al. 1996b, Leese et al. 2008, Kolle et al. 2010). Indeed, we have identified the growth factors and cytokines signaling pathways regulated by the presence of feeders suggesting their putative secretion by the BOEC and VERO. Once again, the regulation of growth factors and cytokines signaling pathways observed at the 16-cell stage are only transient and no huge difference is observed between the modulation induced by the presence of BOEC or VERO (Fig. 6B). Growth factors and cytokines are involved in the regulation of embryonic apoptosis and the cell distribution between ICM and TE (Desai \& Goldfarb 1996, Desai et al. 2007). Among the identified growth factors, IGF1 and FGF2 were reported as maternal support of embryonic growth and development (Kane et al. 1997, Huppertz \& Herrler 2005, Ulbrich et al. 2010) and as enhancers of blastocyst formation in mammals (Kane et al. 1997, Huppertz \& Herrler 2005, Desai et al. 2007, Ulbrich et al. 2010, Velazquez et al. 2011, Kocyigit \& Cevik 2015). Both are known to be secreted by BOEC (SchmaltzPanneau et al. 2015) and IGF1 is also secreted by VERO cells (Duszewska et al. 2000). The putative expression of FGF2 by VERO cells remains to be investigated. Among the identified cytokines, TGFB1 is a regulator of cell proliferation (Kane et al. 1997) and its supplementation during in vitro culture increases mouse blastocyst rate (Paria \& Dey 1990). Previous studies highlighted the expression of TGFB1 by BOEC or bovine oviduct (Desai \& Goldfarb 1996) but it was not detected in supernatant of VERO co-culture system (Desai \& Goldfarb 1996). Besides, several studies have analyzed the influence of a cocktails of growth factors and cytokines on bovine early development, such as IGF1, IGF2, bFGF, LIF,
GM-CSF, TGFB and PDGF (Moreno et al. 2015) or IGF1, IGF2, bFGF, LIF, GM-CSF and TGFB (Neira et al. 2010), always improving blastocyst rates and total number of cells. Surprisingly, whereas some of these factors are known to be expressed by the feeders, our data revealed a downregulation of their signaling pathways in the co-cultured embryos when compared to culture without feeders (Fig. 6). This suggests a competition of autrocrine and paracrine regulation of the signaling pathways of cytokines and growth factors between the embryo and the cells present in proximity, as previously described for the regulation HDGF and TNF signaling pathways in embryos in presence of endometrial cells (Gomez et al. 2014, Correia-Alvarez et al. 2015), reflecting the complexity of the interaction between the embryo and the oviduct/endometrial cells. Accordingly, the regulation of these signaling pathways is certainly implicated in the decrease of blastocyst quality, indirectly and partly mediated by STAT3 and STAT5.

Collectively, our data do not pinpoint to differences between BOEC and VERO co-culture systems in terms of developmental rate or impact on embryo transcriptome (except for the regulation of fatty acid metabolism which appeared differentially regulated regarding the feeders origin only at blastocyst stage). Moreover, no impact on development rates was evidenced when compared to $5 \% \mathrm{O}_{2}$ condition. Contrarily to previous studies (Cordova et al. 2014, Schmaltz-Panneau et al. 2014, 2015), the analysis of blastocyst gene expression suggested a slight decrease in blastocyst quality induced by feeder presence (including BOEC), revealed through an increase in embryonic apoptosis and a decline in cell survival and differentiation. Further experiments would be necessary to better estimate embryo quality obtained in these culture conditions, especially the influence of these co-culture systems on epigenetic and post-translational regulations, on lineages determination and pregnancy outcomes. Besides, the use of other BOEC co-culture systems, such as BOEC vesicles (Lopera-Vasquez et al. 2016) or cell suspension (Rottmayer et al. 2006), oxygen concentration suitable for maintenance of embryo and BOEC viability (Torres et al. 2013) or other culture medium (including sequential culture systems) (Ulbrich et al. 2010) may improve our understanding of factors secreted by oviduct and embryo/oviduct cells cross-talk.

\section{Supplementary data}

This is linked to the online version of the paper at http://dx.doi.org/10.1530/REP-17-0449.

\section{Declaration of interest}

The authors declare that there is no conflict of interest that could be perceived as prejudicing the impartiality of the research reported. 


\section{Funding}

This study and Dr Anaïs Vitorino Carvalho's fellowship were supported by EU FP7 KBBE FECUND.

\section{Acknowledgements}

The authors thank Nathalie Peynot for her precious help concerning RT-qPCR analysis.

\section{References}

Al Darwich A, Perreau C, Petit MH, Papillier P, Dupont J, Guillaume D, Mermillod P \& Guignot F 2010 Effect of PUFA on embryo cryoresistance, gene expression and AMPKalpha phosphorylation in IVF-derived bovine embryos. Prostaglandins and Other Lipid Mediators 93 30-36. (doi:10.1016/j.prostaglandins.2010.06.002)

Amin A, Gad A, Salilew-Wondim D, Prastowo S, Held E, Hoelker M, Rings F, Tholen E, Neuhoff C, Looft C et al. 2014 Bovine embryo survival under oxidative-stress conditions is associated with activity of the NRF2mediated oxidative-stress-response pathway. Molecular Reproduction and Development 81 497-513. (doi:10.1002/mrd.22316)

Ammerman NC, Beier-Sexton M \& Azad AF 2008 Growth and maintenance of Vero cell lines. Current Protocols in Microbiology 11 A.4E.1-A.4E.7 (doi:10.1002/9780471729259.mca04es11)

Bavister BD 1995 Culture of preimplantation embryos: facts and artifacts. Human Reproduction Update 1 91-148. (doi:10.1093/humupd/1.2.91)

Carnegie JA, Durnford R, Algire J, Morgan J 1997 Evaluation of mitomycin-treated vero cells as a co-culture system for IVM/IVF-derived bovine embryos. Theriogenology 48 377-389. (doi:10.1016/S0093691X(97)00249-5)

Carnegie JA, Morgan JJ, McDiarmid N \& Durnford R 1999 Influence of protein supplements on the secretion of leukaemia inhibitory factor by mitomycin-pretreated Vero cells: possible application to the in vitro production of bovine blastocysts with high cryotolerance. Journal of Reproduction and Fertility 117 41-48. (doi:10.1530/jrf.0.1170041)

Clemente M, de la Fuente J, Lonergan P, Gutierrez-Adan A \& Rizos D 2008 Effect of oxygen tension on embryo development and gene transcription of bovine blastocysts produced in vitro by co-culture with oviduct epithelial cells. Biology of Reproduction 78 133. (doi:10.1093/ biolreprod/78.s1.133a)

Cordova A, Perreau C, Uzbekova S, Ponsart C, Locatelli Y \& Mermillod P 2014 Development rate and gene expression of IVP bovine embryos cocultured with bovine oviduct epithelial cells at early or late stage of preimplantation development. Theriogenology 81 1163-1173. (doi:10.1016/j.theriogenology.2014.01.012)

Correia-Alvarez E, Gomez E, Martin D, Carrocera S, Perez S, Peynot N, Giraud-Delville C, Caamano JN, Balseiro A, Sandra O et al. 2015 Early embryonic and endometrial regulation of tumor necrosis factor and tumor necrosis factor receptor 2 in the cattle uterus. Theriogenology 83 1028-1037. (doi:10.1016/j.theriogenology.2014.12.007)

Desai NN \& Goldfarb JM 1996 Growth factor/cytokine secretion by a permanent human endometrial cell line with embryotrophic properties. Journal of Assisted Reproduction and Genetics 13 546-550. (doi:10.1007/BF02066606)

Desai N, Kattal N, AbdelHafez FF, Szeptycki-Lawson J \& Goldfarb J 2007 Granulocyte-macrophage colony stimulating factor (GM-CSF) and coculture can affect post-thaw development and apoptosis in cryopreserved embryos. Journal of Assisted Reproduction and Genetics 24 215-222. (doi:10.1007/s10815-007-9119-8)

Diskin MG \& Morris DG 2008 Embryonic and early foetal losses in cattle and other ruminants. Reproduction in Domestic Animals 43 (Supplement 2) 260-267. (doi:10.1111/j.1439-0531.2008.01171.x)

Duszewska AM, Reklewski Z, Pienkowski M, Karasiewicz J \& Modlinski JA 2000 Development of bovine embryos on Vero/BRL cell monolayers (mixed co-culture). Theriogenology 54 1239-1247. (doi:10.1016/ S0093-691X(00)00430-1)

Eyestone WH \& First NL 1989 Co-culture of early cattle embryos to the blastocyst stage with oviducal tissue or in conditioned medium. Journal of Reproduction and Fertility 85 715-720. (doi:10.1530/jrf.0.0850715)
Gad A, Schellander K, Hoelker M \& Tesfaye D 2012 Transcriptome profile of early mammalian embryos in response to culture environment. Animal Reproduction Science 134 76-83. (doi:10.1016/j. anireprosci.2012.08.014)

Gandolfi F \& Moor RM 1987 Stimulation of early embryonic development in the sheep by co-culture with oviduct epithelial cells. Journal of Reproduction and Fertility 81 23-28. (doi:10.1530/jrf.0.0810023)

Gomez E, Correia-Alvarez E, Caamano JN, Diez C, Carrocera S, Peynot N, Martin D, Giraud-Delville C, Duranthon V, Sandra O et al. 2014 Hepatoma-derived growth factor: from the bovine uterus to the in vitro embryo culture. Reproduction 148 353-365. (doi:10.1530/REP-14-0304)

Guillomot M 1995 Cellular interactions during implantation in domestic ruminants. Journal of Reproduction and Fertility 49 39-51.

Humblot P 2001 Use of pregnancy specific proteins and progesterone assays to monitor pregnancy and determine the timing, frequencies and sources of embryonic mortality in ruminants. Theriogenology $\mathbf{5 6}$ 1417-1433. (doi:10.1016/S0093-691X(01)00644-6)

Huppertz B \& Herrler A 2005 Regulation of proliferation and apoptosis during development of the preimplantation embryo and the placenta. Birth Defects Research Part C: Embryo Today 75 249-261. (doi:10.1002/bdrc.20056)

Jacquier V, Estelle J, Schmaltz-Panneau B, Lecardonnel J, Moroldo M, Lemonnier G, Turner-Maier J, Duranthon V, Oswald IP, Gidenne T et al. 2015 Genome-wide immunity studies in the rabbit: transcriptome variations in peripheral blood mononuclear cells after in vitro stimulation by LPS or PMA-lonomycin. BMC Genomics 16 26. (doi:10.1186/s12864-015-1218-9)

Kane MT, Morgan PM \& Coonan C 1997 Peptide growth factors and preimplantation development. Human Reproduction Update $\mathbf{3}$ 137-157. (doi:10.1093/humupd/3.2.137)

Kocyigit A \& Cevik M 2015 Effects of leukemia inhibitory factor and insulin-like growth factor-I on the cell allocation and cryotolerance of bovine blastocysts. Cryobiology 71 64-69. (doi:10.1016/j. cryobiol.2015.05.068)

Kolle S, Reese S \& Kummer W 2010 New aspects of gamete transport, fertilization, and embryonic development in the oviduct gained by means of live cell imaging. Theriogenology 73 786-795. (doi:10.1016/j. theriogenology.2009.11.002)

Lai YM, Chang MY, Chang FH, Lee CL, Lee JD, Chang SY, Huang HY, Wang ML, Chan PJ \& Soong YK 1996a The effects of Vero cell co-culture on human zygotes resulting from in vitro fertilization and oocytes following subzonal insemination. Changgeng Yi Xue Za Zhi 19 203-210.

Lai YM, Wang HS, Lee CL, Lee JD, Huang HY, Chang FH, Lee JF \& Soong YK 1996b Insulin-like growth factor-binding proteins produced by Vero cells, human oviductal cells and human endometrial cells, and the role of insulin-like growth factor-binding protein-3 in mouse embryo coculture systems. Human Reproduction 11 1281-1286. (doi:10.1093/ oxfordjournals.humrep.a019372)

Lê S, Josse J \& Husson F 2008 FactoMineR: an R package for multivariate analysis. Journal of Statistical Software 25 1-18.

Leese HJ, Hugentobler SA, Gray SM, Morris DG, Sturmey RG, Whitear SL \& Sreenan JM 2008 Female reproductive tract fluids: composition, mechanism of formation and potential role in the developmental origins of health and disease. Reproduction, Fertility, and Development $201-8$. (doi:10.1071/RD07153)

Lequarre AS, Grisart B, Moreau B, Schuurbiers N, Massip A \& Dessy F 1997 Glucose metabolism during bovine preimplantation development: analysis of gene expression in single oocytes and embryos. Molecular Reproduction and Development 48 216-226. (doi:10.1002/(SICI)10982795(199710)48:2<216::AID-MRD9>3.0.CO;2-V)

Lequarre AS, Marchandise J, Moreau B, Massip A \& Donnay I 2003 Cell cycle duration at the time of maternal zygotic transition for in vitro produced bovine embryos: effect of oxygen tension and transcription inhibition. Biology of Reproduction 69 1707-1713. (doi:10.1095/ biolreprod.103.017178)

Li W, Goossens K, Van Poucke M, Forier K, Braeckmans K, Van Soom A \& Peelman LJ 2014 High oxygen tension increases global methylation in bovine 4-cell embryos and blastocysts but does not affect general retrotransposon expression. Reproduction, Fertility and Development 28 948-959. (doi:10.1071/RD14133)

Lopera-Vasquez R, Hamdi M, Fernandez-Fuertes B, Maillo V, BeltranBrena P, Calle A, Redruello A, Lopez-Martin S, Gutierrez-Adan A, YanezMo $M$ et al. 2016 Extracellular vesicles from BOEC in in vitro embryo development and quality. PLOS ONE 11 e0148083. (doi:10.1371/ journal.pone.0148083) 
Maj T \& Chelmonska-Soyta A 2007 Pleiotropy and redundancy of STAT proteins in early pregnancy. Reproduction in Domestic Animals 42 343-353. (doi:10.1111/j.1439-0531.2006.00787.x)

Menck MC, Guyader-Joly C, Peynot N, Le Bourhis D, Lobo RB, Renard JP \& Heyman Y 1997 Beneficial effects of Vero cells for developing IVF bovine eggs in two different coculture systems. Reproduction Nutrition Development 37 141-150. (doi:10.1051/rnd:19970202)

Menezo YJ, Guerin JF \& Czyba JC 1990 Improvement of human early embryo development in vitro by coculture on monolayers of Vero cells. Biology of Reproduction 42 301-306. (doi:10.1095/biolreprod42.2.301)

Meng F, Forrester-Gauntlett B, Turner P, Henderson H \& Oback B 2015 Signal inhibition reveals JAK/STAT3 pathway as critical for bovine inner cell mass development. Biology of Reproduction 93 132. (doi:10.1095/ biolreprod.115.134254)

Mermillod P, Vansteenbrugge A, Wils C, Mourmeaux JL, Massip A \& Dessy F 1993 Characterization of the embryotrophic activity of exogenous protein-free oviduct-conditioned medium used in culture of cattle embryos. Biology of Reproduction 49 582-587. (doi:10.1095/ biolreprod49.3.582)

Moreno D, Neira A, Dubreil L, Liegeois L, Destrumelle S, Michaud S, Thorin C, Briand-Amirat L, Bencharif D \& Tainturier D 2015 In vitro bovine embryo production in a synthetic medium: embryo development, cryosurvival, and establishment of pregnancy. Theriogenology $\mathbf{8 4}$ 1053-1060. (doi:10.1016/j.theriogenology.2015.04.014)

Nakasato $M$, Shirakura $Y$, Ooga $M$, Iwatsuki $M$, Ito $M$, Kageyama S, Sakai S, Nagata M \& Aoki F 2006 Involvement of the STAT5 signaling pathway in the regulation of mouse preimplantation development. Biology of Reproduction 75 508-517. (doi:10.1095/biolreprod.105.047860)

Neira JA, Tainturier D, Pena MA \& Martal J 2010 Effect of the association of IGF-I, IGF-II, bFGF, TGF-beta1, GM-CSF, and LIF on the development of bovine embryos produced in vitro. Theriogenology 73 595-604. (doi:10.1016/j.theriogenology.2009.10.015)

Ouhibi N, Menezo Y, Benet G \& Nicollet B 1989 Culture of epithelial cells derived from the oviduct of different species. Human Reproduction $\mathbf{4}$ 229-235. (doi:10.1093/oxfordjournals.humrep.a136877)

Paria BC \& Dey SK 1990 Preimplantation embryo development in vitro: cooperative interactions among embryos and role of growth factors. PNAS 87 4756-4760. (doi:10.1073/pnas.87.12.4756)

Pegoraro LM, Thuard JM, Delalleau N, Guerin B, Deschamps JC, Marquant Le Guienne B \& Humblot P 1998 Comparison of sex ratio and cell number of IVM-IVF bovine blastocysts co-cultured with bovine oviduct epithelial cells or with Vero cells. Theriogenology 49 1579-1590. (doi:10.1016/S0093-691X(98)00103-4)

Peynot N, Duranthon V \& Khan DR 2015 Gene expression analysis in early embryos through reverse transcription quantitative PCR (RT-qPCR). Methods in Molecular Biology 1222 181-196.

Rho GJ, S B, Kim DS, Son WJ, Cho SR, Kim JG, B MK \& Choe SY 2007 Influence of in vitro oxygen concentrations on preimplantation embryo development, gene expression and production of Hanwoo calves following embryo transfer. Molecular Reproduction and Development 74 486-496. (doi:10.1002/mrd.20502)

Rief S, Sinowatz F, Stojkovic M, Einspanier R, Wolf E \& Prelle K 2002 Effects of a novel co-culture system on development, metabolism and gene expression of bovine embryos produced in vitro. Reproduction 124 543-556. (doi:10.1530/rep.0.1240543)

Rieger D, Grisart B, Semple E, Van Langendonckt A, Betteridge KJ \& Dessy F 1995 Comparison of the effects of oviductal cell co-culture and oviductal cell-conditioned medium on the development and metabolic activity of cattle embryos. Journal of Reproduction and Fertility 105 91-98. (doi:10.1530/jrf.0.1050091)

Rizos D, Ward F, Boland MP \& Lonergan P 2001 Effect of culture system on the yield and quality of bovine blastocysts as assessed by survival after vitrification. Theriogenology 56 1-16. (doi:10.1016/S0093-691X(01)00538-6)

Rottmayer R, Ulbrich SE, Kolle S, Prelle K, Neumueller C, Sinowatz F, Meyer HH, Wolf E \& Hiendleder S 2006 A bovine oviduct epithelial cell suspension culture system suitable for studying embryo-maternal interactions: morphological and functional characterization. Reproduction 132 637-648. (doi:10.1530/rep.1.01136)

Sagirkaya H, Misirlioglu M, Kaya A, First NL, Parrish JJ \& Memili E 2006 Developmental and molecular correlates of bovine preimplantation embryos. Reproduction 131 895-904. (doi:10.1530/rep.1.01021)

Schmaltz-Panneau B, Cordova A, Dhorne-Pollet S, Hennequet-Antier C, Uzbekova S, Martinot E, Doret S, Martin P, Mermillod P \& Locatelli
Y 2014 Early bovine embryos regulate oviduct epithelial cell gene expression during in vitro co-culture. Animal Reproduction Science 149 103-116. (doi:10.1016/j.anireprosci.2014.06.022)

Schmaltz-Panneau B, Locatelli Y, Uzbekova S, Perreau C \& Mermillod P 2015 Bovine oviduct epithelial cells dedifferentiate partly in culture, while maintaining their ability to improve early embryo development rate and quality. Reproduction in Domestic Animals 50 719-729. (doi:10.1111/rda.12556)

Shen XH, Han YJ, Zhang DX, Cui XS \& Kim NH 2009 A link between the interleukin-6/Stat3 anti-apoptotic pathway and microRNA-21 in preimplantation mouse embryos. Molecular Reproduction and Development 76 854-862. (doi:10.1002/mrd.21048)

Smyth G 2005. limma: linear models for microarray data. In Gentleman R, Carey VJ, Huber W, Irizarry RA, Dudoit S, (Editors) Bioinformatics and Computational Biology Solutions using $R$ and Bioconductor. Statistics for Biology and Health. New York, NY: Springer, pp 397-420. (doi:10.1007/0-387-29362-0_23)

Tahir MZ, George F \& Donnay I 2011 Comparison of different membrane supports for monolayer culture of bovine oviduct epithelial cells. BMC Proceedings 5 (Supplement 8) P117. (doi:10.1186/1753-6561-5S8-P117)

Takahashi Y, Hishinuma M, Matsui M, Tanaka H \& Kanagawa H 1996 Development of in vitro matured/fertilized bovine embryos in a chemically defined medium: influence of oxygen concentration in the gas atmosphere. Journal of Veterinary Medical Science 58 897-902.

Takahashi M, Keicho K, Takahashi H, Ogawa H, Schultz RM \& Okano A 2000 Effect of oxidative stress on development and DNA damage in in-vitro cultured bovine embryos by comet assay. Theriogenology 54 137-145. (doi:10.1016/S0093-691X(00)00332-0)

Telford NA, Watson AJ \& Schultz GA 1990 Transition from maternal to embryonic control in early mammalian development: a comparison of several species. Molecular Reproduction and Development 26 90-100. (doi:10.1002/mrd.1080260113)

Tervit HR, Whittingham DG \& Rowson LE 1972 Successful culture in vitro of sheep and cattle ova. Journal of Reproduction and Fertility $\mathbf{3 0}$ 493-497. (doi:10.1530/jrf.0.0300493)

Torres A, Batista M, Diniz P, Mateus L \& Lopes-da-Costa L 2013 Embryoluteal cells co-culture: an in vitro model to evaluate steroidogenic and prostanoid bovine early embryo-maternal interactions. In Vitro Cellular and Developmental Biology Animals 49 134-146. (doi:10.1007/s11626012-9577-x)

Ulbrich SE, Zitta K, Hiendleder S \& Wolf E 2010 In vitro systems for intercepting early embryo-maternal cross-talk in the bovine oviduct. Theriogenology 73 802-816. (doi:10.1016/j. theriogenology.2009.09.036)

Velazquez MA, Hermann D, Kues WA \& Niemann H 2011 Increased apoptosis in bovine blastocysts exposed to high levels of IGF1 is not associated with downregulation of the IGF1 receptor. Reproduction 141 91-103. (doi:10.1530/REP-10-0336)

Walter I 1995 Culture of bovine oviduct epithelial cells (BOEC). Anatomical Record 243 347-356. (doi:10.1002/ar.1092430309)

Watkins AJ, Papenbrock T \& Fleming TP 2008 The preimplantation embryo: handle with care. Seminars in Reproductive Medicine 26 175-185. (doi:10.1055/s-2008-1042956)

Watson AJ, Watson PH, Warnes D, Walker SK, Armstrong DT \& Seamark RF 1994 Preimplantation development of in vitro-matured and in vitrofertilized ovine zygotes: comparison between coculture on oviduct epithelial cell monolayers and culture under low oxygen atmosphere. Biology of Reproduction 50 715-724. (doi:10.1095/biolreprod50.4.715)

Yuan YQ, Van Soom A, Coopman FO, Mintiens K, Boerjan ML, Van Zeveren A, de Kruif A \& Peelman LJ 2003 Influence of oxygen tension on apoptosis and hatching in bovine embryos cultured in vitro. Theriogenology 59 1585-1596. (doi:10.1016/S0093-691X(02)01204-9)

Received 21 July 2017

First decision 22 August 2017

Revised manuscript received 23 August 2017

Accepted 30 August 2017 